\title{
Analysis and evaluation of WRF microphysical schemes for deep moist convection over south-eastern South America (SESA) using microwave satellite observations and radiative transfer simulations
}

\author{
Victoria Sol Galligani ${ }^{1}$, Die Wang ${ }^{2}$, Milagros Alvarez Imaz ${ }^{1}$, Paola Salio ${ }^{1,3}$, and Catherine Prigent ${ }^{2}$ \\ ${ }^{1}$ Centro de Investigaciones del Mar y la Atmófera (CIMA), Instituto Franco Argentino sobre Estudios de Clima y sus \\ Impactos (UMI IFAECI)/CNRS, CONICET - Universidad de Buenos Aires, Buenos Aires, Argentina \\ ${ }^{2}$ Laboratoire d'Etudes du Rayonnement et de la Matière en Astrophysique (LERMA), CNRS, Observatoire de Paris, \\ Paris, France \\ ${ }^{3}$ Departamento de Ciencias de la Atmósfera y los Océanos, Facultad de Ciencias Exactas y Naturales, \\ Universidad de Buenos Aires, Buenos Aires, Argentina
}

Correspondence to: Victoria Sol Galligani (victoria.galligani@cima.fcen.uba.ar)

Received: 10 March 2017 - Discussion started: 3 May 2017

Revised: 4 July 2017 - Accepted: 9 August 2017 - Published: 5 October 2017

\begin{abstract}
In the present study, three meteorological events of extreme deep moist convection, characteristic of southeastern South America, are considered to conduct a systematic evaluation of the microphysical parameterizations available in the Weather Research and Forecasting (WRF) model by undertaking a direct comparison between satellite-based simulated and observed microwave radiances. A research radiative transfer model, the Atmospheric Radiative Transfer Simulator (ARTS), is coupled with the WRF model under three different microphysical parameterizations (WSM6, WDM6 and Thompson schemes). Microwave radiometry has shown a promising ability in the characterization of frozen hydrometeors. At high microwave frequencies, however, frozen hydrometeors significantly scatter radiation, and the relationship between radiation and hydrometeor populations becomes very complex. The main difficulty in microwave remote sensing of frozen hydrometeor characterization is correctly characterizing this scattering signal due to the complex and variable nature of the size, composition and shape of frozen hydrometeors. The present study further aims at improving the understanding of frozen hydrometeor optical properties characteristic of deep moist convection events in south-eastern South America. In the present study, bulk optical properties are computed by integrating the singlescattering properties of the Liu (2008) discrete dipole approximation (DDA) single-scattering database across the particle size distributions parameterized by the different WRF
\end{abstract}

schemes in a consistent manner, introducing the equal mass approach. The equal mass approach consists of describing the optical properties of the WRF snow and graupel hydrometeors with the optical properties of habits in the DDA database whose dimensions might be different $\left(D_{\max }^{\prime}\right)$ but whose mass is conserved. The performance of the radiative transfer simulations is evaluated by comparing the simulations with the available coincident microwave observations up to $190 \mathrm{GHz}$ (with observations from Tropical Rainfall Measuring Mission's (TRMM) Microwave Imager (TMI), Microwave Humidity Sounder (MHS) and Special Sensor Microwave Imager/Sounder (SSMI/S)) using the $\chi^{2}$ test. Good agreement is obtained with all observations provided special care is taken to represent the scattering properties of the snow and graupel species.

\section{Introduction}

The continental region east of the Andes, covering the south of Brazil, Paraguay, Uruguay and the north and centre of Argentina (usually referred to as south-eastern South America, SESA), is known for its large and intense mesoscale convective systems (MCSs) within which severe weather events develop (e.g. Altinger de Schwarzkopf and Necco, 1988; Silva Dias, 2011; Mezher and Barros, 2012; Goodman et al., 
2013; Salio et al., 2015). These are the regions where the strongest MCSs on Earth occur (Zipser et al., 2006). In this data-sparse region, little is known about the aspects of these systems, including what governs their structure, life cycle, similarities and differences with severe weather producing systems observed elsewhere on the Earth, and their predictability from minutes to climate timescales. High-resolution models are a powerful tool for studying convection.

Numerical weather prediction (NWP) models can be used to perform numerical experiments in controlled environmental conditions to assess the impact of different physical processes and environmental conditions upon the life cycle and the organization of convection (e.g. Morrison and Khvorostyanov, 2005). The description of cloud processes and ultimately the dynamical processes that result from numerical models need to be improved to more accurately describe key factors such as hydrometeor characteristics, latent heating profiles, radiative fluxes and forcing, entrainment and cloud updraft and downdraft properties. This is particularly important since, with the increase in computing power in recent years, the physical parameterizations in climate and numerical weather prediction (NWP) models have improved to incorporate microphysical processes, often at increasingly high resolution, resolving the dynamical interactions in convective systems.

Cloud resolving models can be operated with different parameterizations, including different microphysics schemes. In recent years, increasingly detailed bulk cloud microphysics parameterizations have been incorporated into cloud resolving models. Bulk microphysics represent the size spectra of the different hydrometeor species with a particle size distribution function. In this way, microphysics parameterizations predict the development of one or more hydrometeor categories, their interactions and growth and precipitation. Microphysics schemes may differ in the number of predicted species, predicted moments, number of simulated microphysical processes, assumptions regarding the mass-size relationships and size-terminal fall speed relationships and the assumed particle size distributions. An extensive evaluation of existing schemes is needed in order to constrain and reduce the uncertainties associated with the parameterizations. The microphysical properties (e.g. dielectric properties, density, particle size distribution, shape, orientation) of frozen particles have a particularly complex temporal and spatial variability, and lack robust parameterizations.

Microwave radiometry has shown a promising ability in the characterization of frozen particles, as it is able to penetrate and provide insight into the vertical profiles of most clouds, in contrast to infrared and visible observations, which essentially sense cloud tops. At low microwave frequencies, hydrometeors essentially interact with the radiation through emission and absorption. These interactions are well parameterized using only simple assumptions. In contrast, at high microwave frequencies, frozen hydrometeors can sig- nificantly scatter radiation, and the relationship between radiation and hydrometeor populations becomes much more complex. In the model-to-satellite approach, satellite radiances are simulated using outputs from atmospheric models and compared to available observations using a radiative transfer model (e.g. Chaboureau et al., 2008; MeiroldMautner et al., 2007; Galligani et al., 2014). Under cloudy conditions and at high microwave frequencies $(>80 \mathrm{GHz})$, the radiative transfer calculations are more difficult to handle and they strongly depend upon a much more detailed description of the cloud microphysics than the parameterizations that are currently available in NWP models.

In the present study, meteorological events of extreme deep moist convection are considered to conduct a systematic evaluation of the micro-physical parameterizations available in the Weather Research and Forecasting (WRF) model. In order to do this, a direct comparison between satellitebased simulated and observed microwave radiances is proposed by coupling the WRF model with a research radiative transfer model, the Atmospheric Radiative Transfer Simulator (ARTS). Since the simulation of passive microwave radiances requires good knowledge of the scattering properties of frozen hydrometeors, the present study further aims at improving the understanding of frozen hydrometeor optical properties and the characteristics of deep convection in the SESA region. This study is structured as follows. Section 2 introduces a particular deep moist convection event in the SESA region, together with a description of the models used and the available microwave observations. This section includes a discussion of the modelling system developed in the present study that converts WRF outputs to simulated microwave brightness temperatures (BTs). Section 3 focuses on the difficulties associated with providing the radiative transfer model used with a rather accurate description of the radiative properties of the hydrometeors modelled by WRF, especially for frozen hydrometeors. A sensitivity study of the passive radiative transfer simulations to the hydrometeor characteristics is presented in Sect. 4 for specific observed transects, followed by a statistical analysis of the simulated and observed brightness temperature distributions. Section 5 further tests the drawn conclusions by simulating two other convective events in the region. Finally, Sect. 6 presents the conclusions and details future work being carried out to exploit this modelling system.

\section{A severe weather event associated with deep convection in the SESA region: models and observations}

The focus of the present study is an intense MCS event observed over the centre of Argentina on 6 December 2012. On 6 and 7 December, the centre of Argentina was affected by many severe weather events, including tornadoes, winds above $100 \mathrm{~km} \mathrm{~h}^{-1}$ and intense precipitation that caused tragic 
flooding in the city of Buenos Aires. The following subsections describe the observations available during this meteorological event, the configuration used in the WRF model runs and its microphysics parameterizations and the radiative transfer model used.

\subsection{Coincident satellite observations}

For the MCS event on 6 December 2012 there are coincident observations available from the Tropical Rainfall Measuring Mission (TRMM) at 07:00 UTC and the Microwave Humidity Sounder (MHS) onboard NOAA-19 at 19:00 UTC. TRMM carries a suite of instruments designed to study precipitation in the tropics (Kummerow et al., 1998). The Tropical Rainfall Measuring Mission's (TRMM) Microwave Imager (TMI) is a conical imager operating at 10.7, 19.4, 21.3, 37 and $85.5 \mathrm{GHz}$ with a $53^{\circ}$ incidence angle. It has two orthogonal polarizations (except at $22 \mathrm{GHz}$ ) and spatial resolutions between $63 \mathrm{~km} \times 37 \mathrm{~km}$ and $7 \mathrm{~km} \times 5 \mathrm{~km}$, depending on the channel. It covers a swath of $780 \mathrm{~km}$. The TRMM Precipitation Radar (PR) operates at $13.8 \mathrm{GHz}$ with a $4 \mathrm{~km}$ resolution and a swath of $220 \mathrm{~km}$. The swath is located in the centre of the TMI swath. The MHS is a cross-track sounder with surface zenith angles varying between 0 and $58^{\circ}$. The channels are located at 89.0, 157.0, 183.3 $\pm 1,183.3 \pm 3$ and $190.3 \mathrm{GHz}$. The channels near the water vapour line of $183.3 \mathrm{GHz}$ are strongly sensitive to atmospheric absorption, in contrast to the more transparent window channels at 89,157 and $190 \mathrm{GHz}$. The spatial resolution at nadir is $16 \mathrm{~km}$ for all channels and increases away from nadir $(26 \mathrm{~km}$ at the furthest zenith angle along track). The polarization state for each channel is a combination between the two orthogonal linear polarizations ( $\mathrm{V}$ and $\mathrm{H}$ ), where the polarization mixing depends on the scanning angle. TMI observations at 10.7, 19.4, 37 and $85.5 \mathrm{GHz}$ are shown in Fig. 1a$\mathrm{d}$ for vertical (V) polarizations only. The highly scattering MCS event is evidenced by brightness temperature depressions at the higher-frequency channels $(\geq 37 \mathrm{GHz})$. At the lower-frequency channels $(\leq 37 \mathrm{GHz})$, TMI is mostly sensitive to surface emission and cloud absorption and emission. The ocean surface emissivities are rather low and polarized, contrary to land surfaces that usually have a high emissivity with limited polarization. For low atmospheric opacity at the lower frequencies, the contrast between ocean and land is larger. This contrast can easily be seen up to $19 \mathrm{GHz}$ in Fig. 1 . At $37 \mathrm{GHz}$, both liquid water emission in clouds and frozen hydrometeor scattering induce a decrease in BT over the high emitting land. At the higher-frequency channel of $85.5 \mathrm{GHz}$, cloud structures appear cold due to the strong scattering of frozen hydrometeors, with rather low BTs (down to almost $50 \mathrm{~K}$ on this case study). Figure 1e shows the PR reflectivity and the PR retrieved freezing level height crossing the MCS system along the black line shown in Fig. 1d. MHS observations at $89,157,183 \pm 1$ and $190 \mathrm{GHz}$ are shown in Fig. 2a$\mathrm{d}$ (the $183 \pm 3$ channel is very similar to $190 \mathrm{GHz}$ and is not shown). Note that MHS zenith angles vary between $58^{\circ}$ (to the west) and $0^{\circ}$ (to the east). In the window channels, the observations over the ocean present rather low brightness temperatures due to the low ocean emissivity when compared to those over the continental region. With increasing atmospheric opacity in the $\mathrm{H}_{2} \mathrm{O}$ water vapour line, as evidenced at $183 \pm 1 \mathrm{GHz}$, the contrast between land and ocean disappears. In the window channels, the scattering effect due to the presence of convection can be observed from the brightness temperatures depressions that increase with frequency, especially in the window channels. The strong brightness temperature depressions that are observed even in the water vapour line channel $(\mathrm{BTs} \approx 100 \mathrm{~K})$ evidence the presence of highly scattering clouds. The following subsections describe the models exploited to use this meteorological event in a systematic evaluation of microphysical parameterizations.

\subsection{The mesoscale cloud model: the WRF model and the WSM6, WDM6 and THOM microphysics options}

WRF is a non-hydrostatic mesoscale numerical weather prediction system designed for both atmospheric research and operational forecasting needs. It provides a full description of the atmospheric parameters (pressure, temperature and prognostic water substance variables). In the present study, WRF-ARW (Skamarock and Klemp, 2008) version 3.6 is used for the model simulations considering only one domain with $4 \mathrm{~km}$ grid spacing and 38 vertical levels. The model was initialized with GFS (Global Forecast System) initial conditions of $0.5^{\circ}$ resolution at 00:00 UTC for 6 December 2012. The model was integrated up to $36 \mathrm{~h}$ with updates of the boundary conditions taken every $3 \mathrm{~h}$ from GFS analysis also at $0.5^{\circ}$ resolution. Figure 3 shows the domain considered, and Table 1 presents the different parameterizations used in the model run.

The three microphysics schemes used in the present study include the WRF single-moment 6 (WSM6; Hong and Lim, 2006), the WRF double-moment 6 (WDM6; Hong et al., 2010) and the Thompson schemes (THOM; Thompson et al., 2008). The three schemes have the same number of water species (water vapour, cloud water, rainwater, cloud ice, snow and graupel). The WSM6 is a single-moment scheme that prognoses the mass mixing ratio of species, whereas the WDM6 is a double-moment scheme based on the WSM6 that additionally prognoses the number concentration mixing ratios of cloud water and rainwater related to the size distribution of the species, i.e. double-moment representation of warm rain. The THOM scheme also additionally prognoses number concentration mixing ratios for cloud ice and warm rain.

These microphysics schemes generally assume a gamma particle size distribution (PSD) for precipitating hydrometeor 


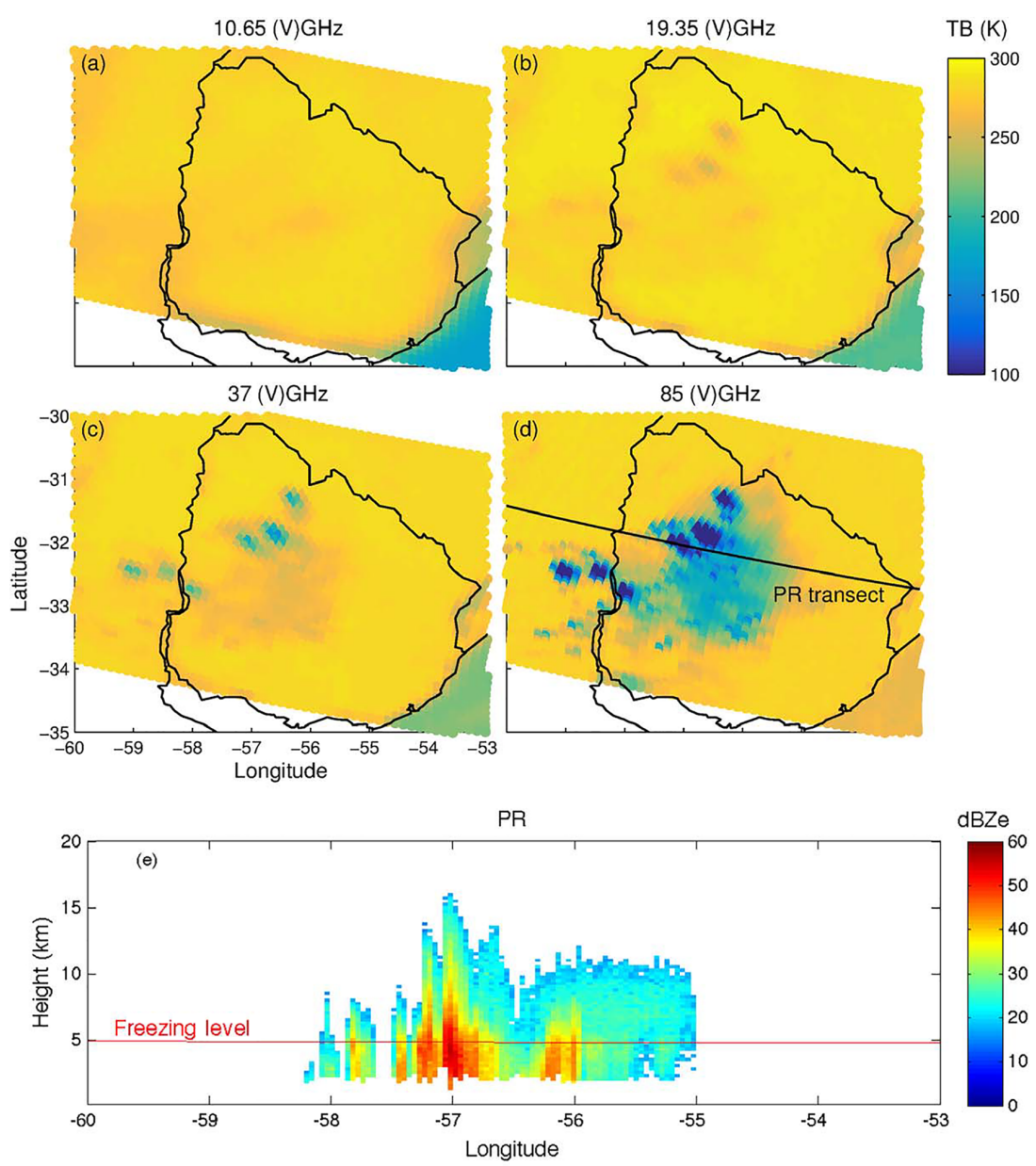

Figure 1. TMI observations on 6 December 2012 at 07:00 UTC for an MCS event of interest in the present study. Note that the horizontally polarized channels and the $22 \mathrm{~V} \mathrm{GHz}$ channel observations are not shown. The solid black line in (d) represents the location of the PR transect shown in (e).

species of the form

$N_{x}(D)=\int N_{0 x} D^{\mu_{x}} e^{\lambda_{x} D} \mathrm{~d} D$,

where $N_{x}(D)$ represents the number concentration $\left(\mathrm{m}^{-1} \mathrm{~m}^{-3}\right)$ of particles of a given hydrometeor class $(x)$ and diameter $D, N_{0 x}$ is the $y$ intercept parameter, $\lambda_{x}$ is the slope parameter and $\mu_{x}$ is the shape parameter of the distribution. This gamma distribution is simplified to an exponential distribution by setting $\mu_{x}$ to zero for rainwater, snow and graupel in both the WSM6 and WDM6 schemes, and for rainwater and graupel in the THOM scheme. Snow is unique in the THOM scheme because, in contrast to most WRF bulk schemes, its particle size distribution is not an exponential size distribution, but a sum of two gamma functions following observations by Field et al. (2005). The particle size distribution, hereafter referred to as the Field et al. (2005) size distribution, is based on in situ observations valid for tropical and midlatitude clouds, and has been used with positive results in recent validation studies (e.g.
Doherty et al., 2007; Kulie et al., 2010). The WSM6 and WDM6 schemes, like most models, use a spherical and constant-density snow assumption through the application of a mass-diameter relationship, usually with a power law $m(D)=\left(\rho_{\mathrm{s}} \pi / 6\right) D^{3}$, where $\rho_{\mathrm{s}}$ is the assumed fixed density of snow (for WSM6/WDM6 $\rho_{\mathrm{s}}=0.1 \mathrm{~kg} \mathrm{~m}^{-3}$ ) and $D$ is the particle maximum diameter. Unlike most schemes, snow density in the THOM scheme is not fixed, but varies with size through the mass-size relationship $m(D)=0.069 D^{2}$. This is an important difference since observational studies rarely support fixed density snow habits. Magono (1965) and many later studies recognize that a size-independent density is not a physically sound assumption for snowflakes because of the rigidity of ice and the nature of the snow formation processes (Leinonen et al., 2012). In this sense, the THOM scheme considers snow to be primarily composed of fractal-like aggregated crystals (Thompson et al., 2008), rather than spherical constant snow crystals, which is a much more realistic approach than the WSM6/WDM6 schemes. The Field et al. (2005) PSD takes into account 


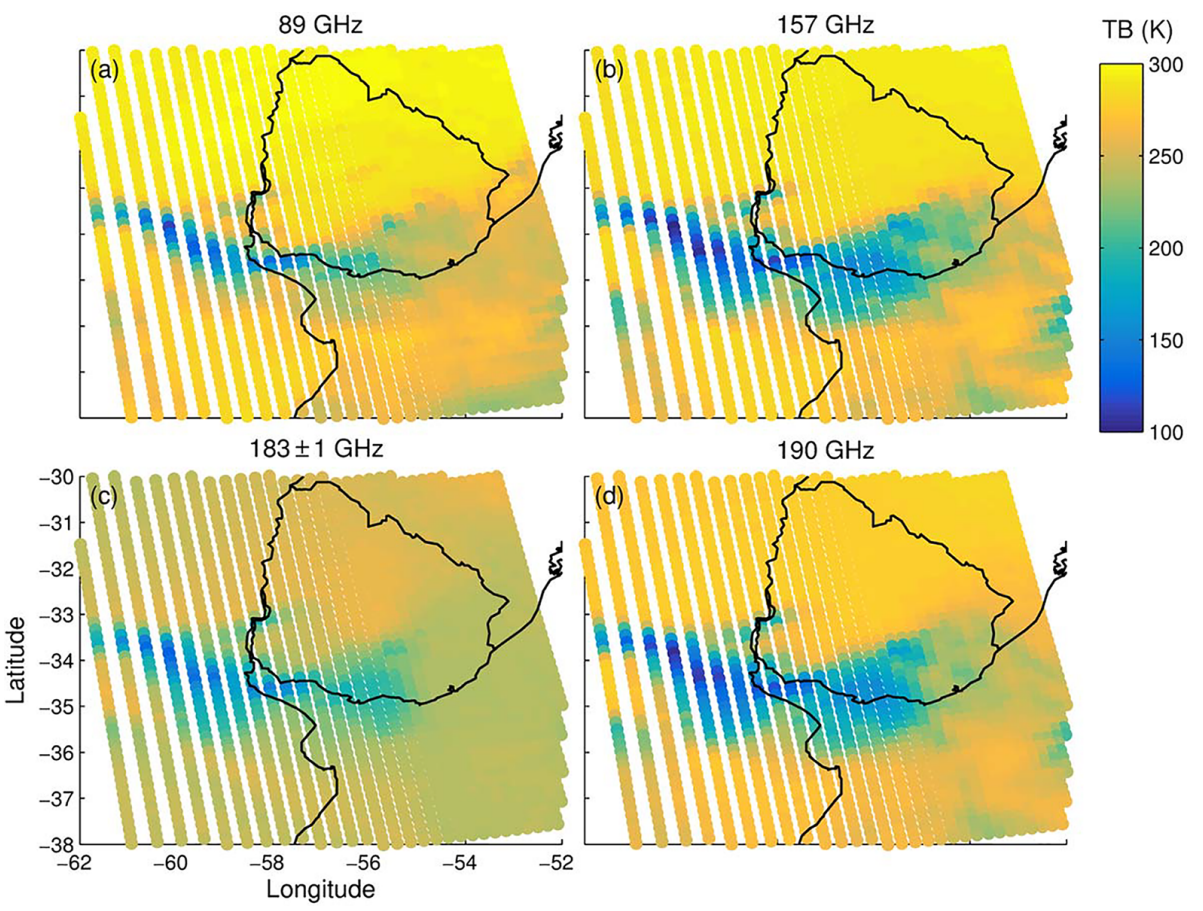

Figure 2. MHS observations on 6 December 2012 at 19:00 UTC for an MCS event of interest in the present study. Note that the 183 \pm 3 GHz channel is not shown.

Table 1. The WRF parameterizations used.

\begin{tabular}{ll}
\hline Physics & Parameterization \\
\hline Microphysics & $\begin{array}{l}\text { WRF single-moment 6 (WSM6, Hong and } \\
\text { Lim, 2006) } \\
\text { WRF double-moment 6 (WDM6, Hong } \\
\text { et al., 2010) } \\
\text { Thompson (THOM; Thompson et al., 2008) }\end{array}$ \\
$\begin{array}{l}\text { Long-wave } \\
\text { radiation }\end{array}$ & RRTM (Mlawer et al., 1997) \\
$\begin{array}{l}\text { Shortwave } \\
\text { radiation } \\
\begin{array}{l}\text { Surface-layer } \\
\text { exchange } \\
\text { coefficient }\end{array}\end{array}$ & Donin-Obukhov (Janjic Eta) scheme \\
$\begin{array}{l}\text { Surface } \\
\text { processes }\end{array}$ & Noah LSM (Chen and Dudhia, 2001) \\
$\begin{array}{l}\text { Plantary } \\
\text { boundary } \\
\text { layer }\end{array}$ & MYJ Janjic (Janjic, 1994) \\
\hline
\end{tabular}

the parameters of the mass-size relationship and predicts a higher number of smaller particles, but a smaller number of larger particles than the WSM6/WDM6 schemes. It is also worth stating that the graupel species in the THOM scheme represent rimed ice (e.g. hybrid-like graupel-hail category) by using a two-parameter diagnostic dependence of its size distribution intercept parameter based on the mass mixing ratio and amount of supercooled liquid water.
Figure 4 shows the integrated column content in $\mathrm{kg} \mathrm{m}^{-2}$ for rain (panels a-c), snow (panels $d-f$ ) and graupel (panels $\mathrm{g}-\mathrm{i}$ ), as simulated by the three different schemes at 19:00 UTC with a minimum threshold of $0.05 \mathrm{~kg} \mathrm{~m}^{-2}$. Note that the integrated content for cloud ice and cloud water are not shown. This specific time output corresponds to the overpass of the MHS discussed above. Another time output considered in the present study is the TRMM overpass at 07:00 UTC (not shown). The black line in Fig. 4g represents an MHS transect simulated which is explored in Sect. 4. A first look at Fig. 4 shows that the three schemes model the structure and the location of the cloud system fairly similarly. The brightness temperature depressions observed in Fig. 2 (and Fig. 1) correspond to the cloud structures simulated by WRF in Fig. 4 at 19:00 UTC (and at 07:00 UTC not shown). A close examination of MHS (and TMI) observations (Fig. 2) Fig. 1 and the WRF cloud outputs in Fig. 4 (not shown for TMI passage time), however, reveals that the cloud system modelled by WRF is slightly time lagged and misplaced with respect to the observations. A closer look at the mass loading of the different hydrometeor also evidences a strong sensitivity to the microphysical scheme used.

Validation techniques of these schemes depend upon the availability of observations. In situ measurements are essential for detailed and direct microphysics validations, such as particle size distributions and liquid / ice water content. However, these observations are limited to certain field campaigns as well as certain parts of the storms. On the other 


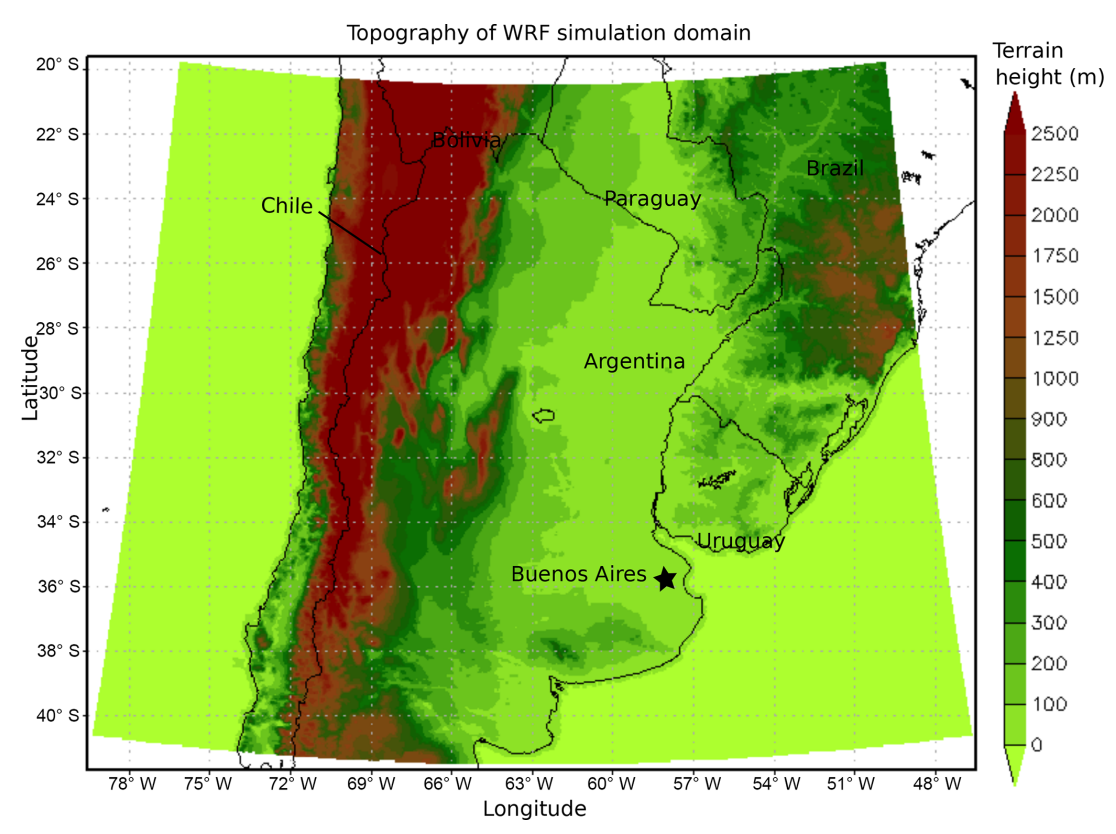

Figure 3. The geographical domain used in WRF model runs illustrated by the topography of the region in metres.

hand, satellite observations can cover this gap if they are widely available and are very useful for model validation. Figure 4 shows that the WSM6 and the WDM6 schemes model similar hydrometeor mass loadings and storm morphology. This is expected as the WDM6 is developed from the processes in the WSM6 scheme. The THOM scheme, on the other hand, shows much higher snow content as reported in many studies (e.g. Kim et al., 2013; Gallus Jr. and Pfeifer, 2008). Figure 5 further shows the domain-averaged vertical distribution of the hydrometeor content modelled by the different schemes between 18:00 and 19:00 UTC. Units are $\mathrm{g} \mathrm{kg}^{-1}$ for all the species. Both Figs. 4 and 5 show comparable behaviour in the frozen phase (ice, snow and graupel) in the WSM6 and WDM6 schemes. This is expected because the WDM6 scheme follows the cold rain processes of the WSM6 scheme and the added processes in the WDM6 do not affect the frozen phases directly (Lim and Hong, 2010). Comparing the warm rain processes of the WSM6 and WDM6 schemes, Fig. 5 shows an increase in the WDM6 rainwater mixing ratio below $5 \mathrm{~km}$ with lower cloud droplet mixing ratios, as reported by Kim et al. (2013), who studied a typhoon event and reported that the liquid phase in the WDM6 scheme produced a significantly greater amount of rainwater but a lower cloud droplet mixing ratio. Various studies have shown that the double-moment approach in the WDM6 scheme may help to achieve a more realistic simulation of convective rain and rainfall retrievals, as the rain number concentration plays an important role in determining the precipitation rate and storm morphology because it modulates the related microphysics terms, in particular, the evaporation rate (Morrison et al., 2009; Li et al., 2009a, b; Lim and Hong, 2010). Figure 4 shows that the THOM scheme predicts the least rainwater, while Fig. 5 further shows that the THOM scheme is dominated by snow throughout the vertical profile. These conclusions are also reached by Kim et al. (2013). The THOM scheme has a maximum cloud water content between 8 and $10 \mathrm{~km}$. This peak of enhanced cloud water content is found within and around strong convective updrafts (Otkin et al., 2003). In order to compare the distribution of the frozen hydrometeor species among the total frozen phase for each scheme, Fig. 5 additionally shows the mean vertical profile of the total frozen content (i.e. ice + snow + graupel, shown in light blue). The total frozen content is comparable in magnitude in all the schemes analysed but since each scheme has different intrinsic assumed characteristics and microphysical processes, they partition the total content in different ways between graupel, cloud ice and snow. The THOM scheme has the most prominent vertical structure. Note that very similar remarks can be drawn from the model simulations at 07:00 UTC in coincidence with the available TMI observations (not shown).

\subsection{The radiative transfer model: ARTS}

A robust radiative transfer model allows consistently modelling of passive observations when using (1) WRF outputs to describe the atmospheric profiles as discussed above and (2) a rather accurate description of the radiative properties of the hydrometeors in each model grid point. In the present study, ARTS (Eriksson et al., 2011), is used. ARTS is a very flexible tool, capable of modelling different atmospheric conditions and different sensor configurations. ARTS is constructed with open-source code available at http://www.radiativetransfer.org along with extensive doc- 


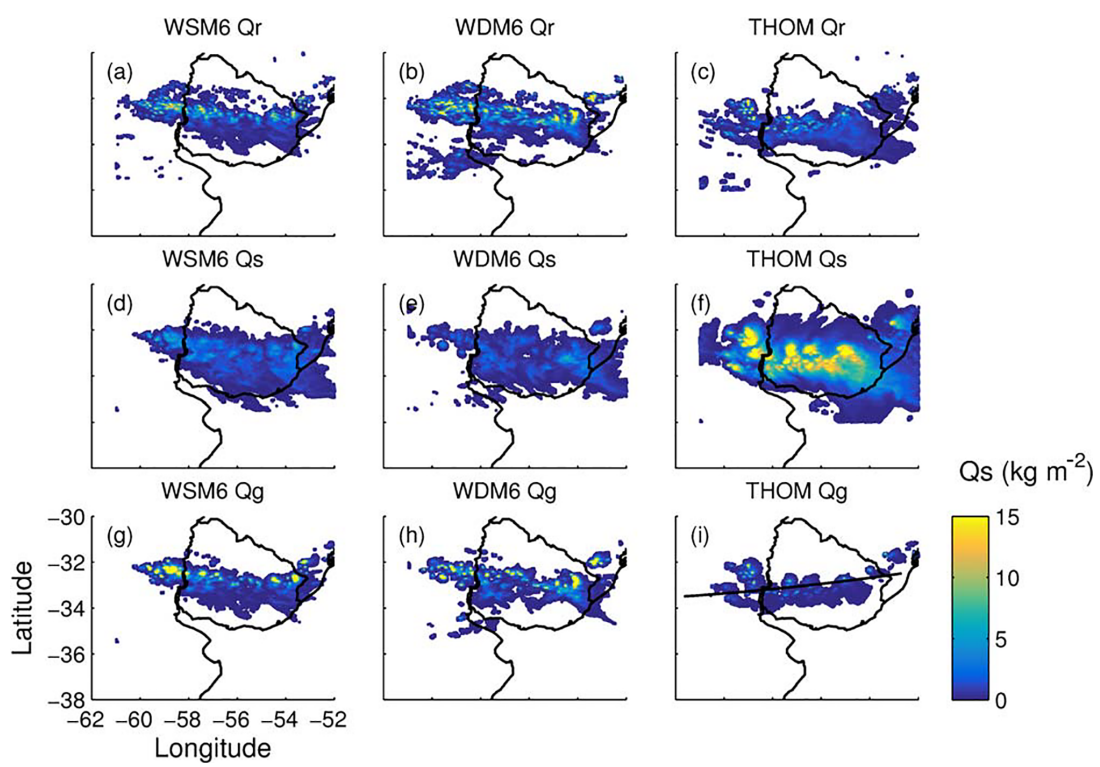

Figure 4. The integrated column content in $\mathrm{kg} \mathrm{m}^{-2}$ for rain, snow and graupel, as simulated by the WRF microphysics options WSM6, WDM6 and THOM, at 19:00 UTC with a $0.05 \mathrm{~kg} \mathrm{~m}^{-2}$ minimum threshold. Note that cloud water and cloud ice are not shown. The black solid line in (i) represents an MHS transect explored in Sect. 4.

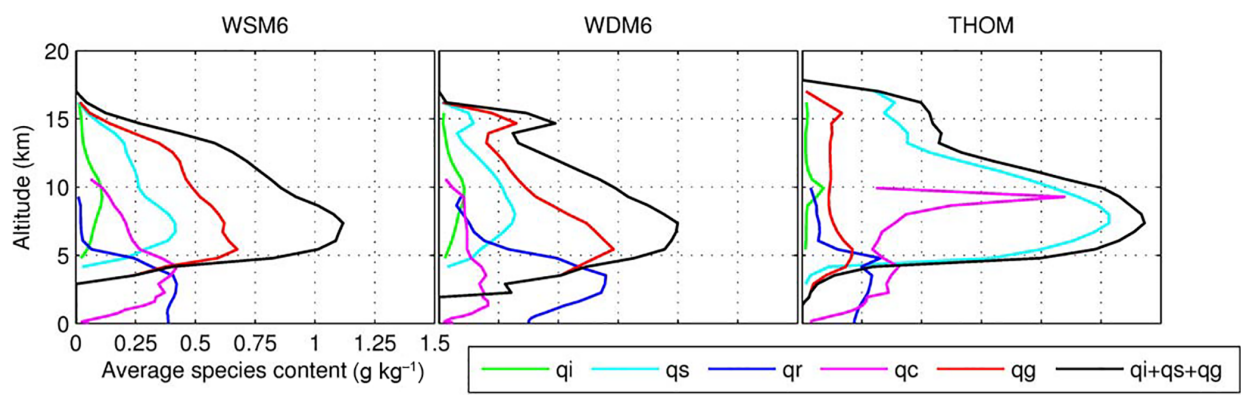

Figure 5. The domain-averaged vertical species content as modelled by WRF between 18:00 and 19:00 UTC by the WSM6, WDM6 and THOM microphysics options. Units are in $\mathrm{g} \mathrm{kg}^{-1}$ for all species, and the domain average is calculated from Fig. 4.

umentation. It is a well-validated model (Melsheimer et al., 2005; Buehler et al., 2006; Saunders et al., 2007) and it can handle scattering with arbitrary complex scattering properties set by the user. It provides a Monte Carlo module to solve the radiative transfer equation under cloudy conditions (Davis et al., 2007) which takes full account of the 3-D description of the atmospheric state modelled by the WRF outputs.

To accurately simulate real microwave observations of satellite-based instruments with ARTS, it is important to have a correct description of the surface properties, the observation geometry and the cloud optical properties. The proposed methodology involves a series of coupling tools. The Tool to Estimate Land Surface Emissivities from Microwave to Sub-millimeter waves (TELSEM2; Wang et al., 2016) and the Tool to Estimate Sea Surface Emissivity from Microwave to Sub-millimeter waves (TESSEM2; Prigent et al., 2016) are used to determine land and ocean surface emissivities respec- tively. TELSEM2 provides the emissivity ( $\mathrm{V}$ and $\mathrm{H}$ components) for any location, month and incidence angle with a spatial resolution of $0.25^{\circ}$. TESSEM calculates sea surface emissivities from wind, sea surface temperature and viewing angle. Coupling WRF outputs with ARTS further requires a good description of the hydrometeor optical properties (i.e. the single-scattering properties) and particle size distributions. Bulk optical properties are computed by integrating the single-scattering properties of particles across a given particle size distribution. The bulk optical properties of the hydrometeors at each model level have a strong influence on the radiative transfer equation for both passive and active simulations. The single-scattering properties are determined by hydrometeor composition, density, dielectric properties, size, shape and orientation. While the particle size distribution of species is intrinsic to each WRF microphysics scheme, cloud resolving models like WRF do not determine all of the parameters needed to determine the single-scattering proper- 
ties, and further assumptions are necessary. This is discussed in more detail in Sect. 3 below.

\section{Modelling the single-scattering properties}

Throughout the present study, the goal when implementing the single-scattering properties and the particle size distribution of the hydrometeor species in ARTS is to remain as consistent as possible with the corresponding WRF microphysics scheme. The particle size distributions for each hydrometeor category in the radiative transfer simulations remains consistent with the parameterizations used in the WRF. The single-scattering properties of hydrometeors, on the other hand, require assumptions to be made.

For simplicity, the optical properties of cloud ice, cloud water and rain are held constant and represented by Mie spheres with the dielectric properties of Liebe et al. (1991) for liquid species and Mätzler (2006) for ice crystals. These are reasonable assumptions for the liquid phase. The mass loadings of ice crystals simulated by WRF in the scenes explored are negligible and, at the microwave frequencies analysed, small pure ice crystals produce very little scattering. Modelling snow and graupel species, on the other hand, is much more challenging, mainly due to uncertainties in their composition and shape. Frozen hydrometeors have high spatial and temporal variability and are of a complex non-spherical nature. Frozen hydrometeors can be both single crystals (with shapes including needles, plates, columns, rosettes, dendrites, etc.) or aggregates (e.g. Baran, 2012). There is a highly complex mixture of differently shaped and sized habits in the atmosphere, and this mixture further varies with particle size. However, the only computationally realistic approach is to assume a one-shape model to represent the total habit population even if this approach does not fully capture the large variability observed in nature.

There are a number of approaches used to model frozen hydrometeors. One is to assume that the habits have certain known realistic shapes like plates or rosettes, and calculate their single-scattering properties using the DDA approach (Draine and Flatau, 1994). The second approach is to approximate these complex shapes with spheres with the same mass and apply Mie theory. This imaginary sphere can either be a pure ice sphere with a smaller diameter or a "soft sphere" of the same size but with lower density and a reduced effective dielectric constant. In the soft sphere approximation, particles are considered to be homogeneous mixtures of ice / air or possibly ice / air / liquid water. This approach requires that the mass fraction of, for example air in the ice / air mixture and the corresponding dielectric properties of the homogeneous mixture, be determined. The soft sphere approximation has been widely used together with the $T$ matrix method to model spheres and spheroids (e.g. Galligani et al., 2014), where the air fraction was either set to be fixed or derived from mass-size parameterizations or snow habit densi-
Table 2. Overview of the Liu (2008) database.

\begin{tabular}{lrrr}
\hline Habit & $\begin{array}{r}\text { Range of max } \\
\text { dimension }(\mu \mathrm{m})\end{array}$ & $a$ & $b$ \\
\hline Long hexagonal column & $121-4835$ & 37.09 & 3.00 \\
Short hexagonal column & $83-3304$ & 116.12 & 3.00 \\
Block hexagonal column & $66-2532$ & 229.66 & 3.00 \\
Thick hexagonal column & $81-3246$ & 122.66 & 3.00 \\
Thin hexagonal column & $127-5059$ & 32.36 & 3.00 \\
Three-bullet rosette & $50-10000$ & 0.32 & 2.37 \\
Four-bullet rosette & $50-10000$ & 0.06 & 2.12 \\
Five-bullet rosette & $50-10000$ & 0.07 & 2.12 \\
Six-bullet rosette & $50-10000$ & 0.09 & 2.13 \\
Sector snowflake & $50-10000$ & 0.002 & 1.58 \\
Dendrite snowflake & $75-12454$ & 0.01 & 1.90 \\
\hline
\end{tabular}

ties. This approach, however, has been shown to be problematic, as the air fraction in the mixing rule must be allowed to vary with both particle size and frequency for a better fit (e.g. Galligani et al., 2014; Eriksson et al., 2015). Liu (2004) showed that the optimal "softness parameter", or effective density, varies with frequency. However, using density-based air fractions which are a function of frequency and size is an unphysical approach. Furthermore, for large particles in the more realistic size dependent mass parameterizations as in the THOM scheme, it has been observed that the larger particles have high air fractions and consequently negligible scattering efficiencies (e.g. Galligani et al., 2014). Although the DDA approach can accurately evaluate the radiative properties of more realistic, complex shapes, choosing a particular shape model remains arbitrary and hence problematic. Readers are encouraged to refer to Eriksson et al. (2015) for a detailed discussion on the microwave optical properties of frozen hydrometeors.

In this study, both snow and graupel hydrometeors are modelled using the same scattering properties of realistic snowflake habits from the Liu (2008) database. Liu (2008) used the DDA code of Draine and Flatau (1994) to compute the single-scattering properties of differently shaped ice crystals. The Liu (2008) database presents 11 different randomly oriented ice crystals at 22 frequencies $(3.0-340 \mathrm{GHz})$ and at 5 different temperatures $(233,243,253,263$ and $273 \mathrm{~K})$. The main properties of the database are listed in Table 2. The soft sphere approximation is also used for comparison, and following the conclusions drawn in Eriksson et al. (2015), the Maxwell-Garnett (1906) mixing rule for "air in ice" is used to model the effective dielectric properties, as it appears to have the least deviation from DDA scattering properties.

The snow and graupel contents are thus described by the corresponding WRF particle size distribution and their single-scattering properties by the Liu (2008) database. One last remark must be made when using the Liu (2008) database to describe the scattering properties of snow and graupel consistently with the WRF microphysics parameter- 


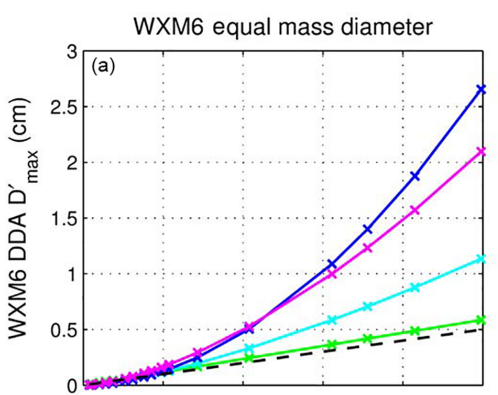

THOM equal mass diameter

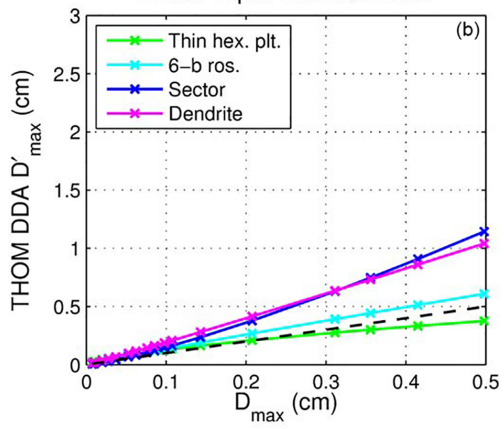

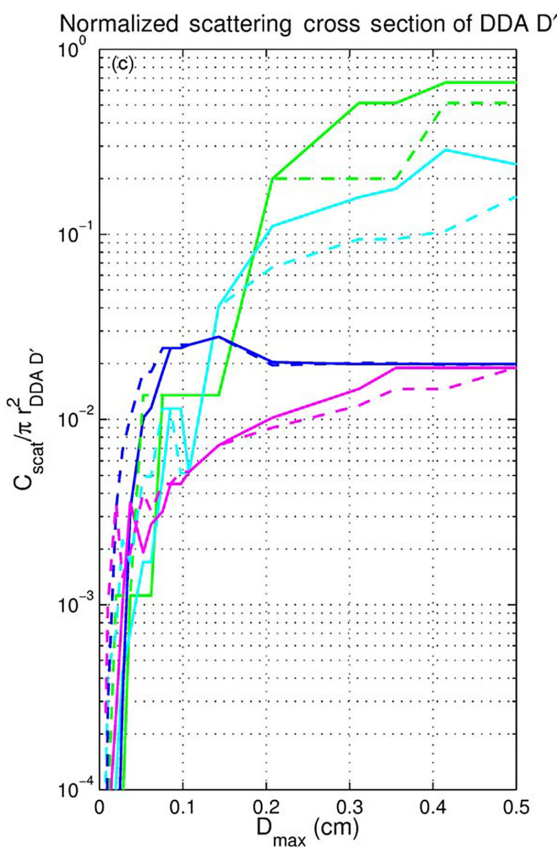

Figure 6. (a, b) The corresponding equal mass DDA habit size calculated from Eq. (3) for WRF (a) WSM6, WDM6 and (b) THOM schemes. (c) The normalized scattering cross sections of the equal mass DDA sized habits ( $D_{\max }^{\prime}$ ) as a function of $D_{\max }$ at $150 \mathrm{GHz}$ and at $263 \mathrm{~K}$ for the WSM6/WDM6 (solid lines) and the THOM scheme (dashed lines).

izations. Both the DDA habits and the WRF schemes use a mass-size relationship of the form

$m=a D_{\max }^{b}$,

where $a$ and $b$ are parameters intrinsic to each of the DDA habits in the Liu (2008) database or each of the hydrometeor species in the microphysics schemes, and indirectly determine the habit density. As described in Sect. 2.2, the snow mass in the THOM scheme is not fixed with size and follows $m(D)=0.069 D^{2}$ while the WSM6 and WDM6 schemes have a constant mass value determined by $m(D)=$ $\left(\rho_{\mathrm{s}} \pi / 6\right) D^{3}$ where $\rho_{\mathrm{s}}=0.1 \mathrm{~kg} \mathrm{~m}^{-3}$. Graupel species in the WSM6, WDM6 and THOM schemes have a constant density of $\rho_{\mathrm{g}}=0.4 \mathrm{~kg} \mathrm{~m}^{-3}$ and follow $m(D)=\left(\rho_{\mathrm{g}} \pi / 6\right) D^{3}$. Similarly, each of the Liu (2008) habits are described by different $a$ and $b$ parameters listed in Table 2 . In order to consistently simulate WRF model outputs with the Liu (2008) habits, the approach used in the present study is to assume an equal mass habit where

$a_{\mathrm{WRF}} D_{\max }^{b_{\mathrm{WRF}}}=a_{\mathrm{LIU}} D_{\max }^{\prime b_{\mathrm{LIU}}}$.

In Eq. (3), $D_{\max }$ is inferred from WRF parameterizations and is used in the particle size distribution. $D_{\max }^{\prime}$ is the corresponding equal mass DDA habit size used to describe the scattering properties of the WRF species consistently. This discussion is important since particle size is a key parameter in single-scattering calculations. Figure $6 a$ and $b$ show the corresponding equal mass $D_{\max }^{\prime}$ for a selected number of Liu (2008) habits when using the WSM6/WDM6 and THOM schemes respectively. The choice of DDA habits shown is a result of regrouping certain habits that behave similarly, such as the thin hexagonal column, the long hexagonal column, the short hexagonal column and the thick hexagonal column, or the bullet rosettes. Note that the included black dashed line represents unity. As shown in Fig. 6a and b, for a given maximum particle dimension in WRF, the equal mass DDA habit $D_{\max }^{\prime}$ can be very different for each of the Liu (2008) habits. Figure 6a and b also show that the equal mass DDA habit $D_{\max }^{\prime}$ is larger when using the WSM6 and WDM6 schemes than when using the THOM scheme. This is expected due to the intrinsic $\rho_{\mathrm{s}}$ differences in these schemes. For the most compact habits of the DDA database, like columns and plates, the difference in $D_{\max }^{\prime}$ between the WSM6/WDM6 and the THOM schemes is the smallest, while the largest differences are seen for the dendrite and sector habits, especially at larger $D_{\max }$. The thin hexagonal plates for example, have equal mass $D_{\max }^{\prime}$ diameters above $D_{\max }$ for the WSM6/WDM6, and equal mass $D_{\max }^{\prime}$ diameters below $D_{\max }$ in the THOM scheme. The six-bullet rosette equal mass $D_{\max }^{\prime}$ is greater for the WSM6/WDM6 schemes but close to unity for the THOM scheme. Figure $6 \mathrm{c}$ shows the normalized scattering cross sections at $150 \mathrm{GHz}$ of the corresponding equal mass WSM6/WDM6 (THOM) $D_{\max }^{\prime}$ habits as a function of $D_{\max }$ in solid lines (dashed lines). Figure 6c shows that, in general, WSM6/WDM6 normalized scattering cross sections are larger than the THOM scheme, es- 

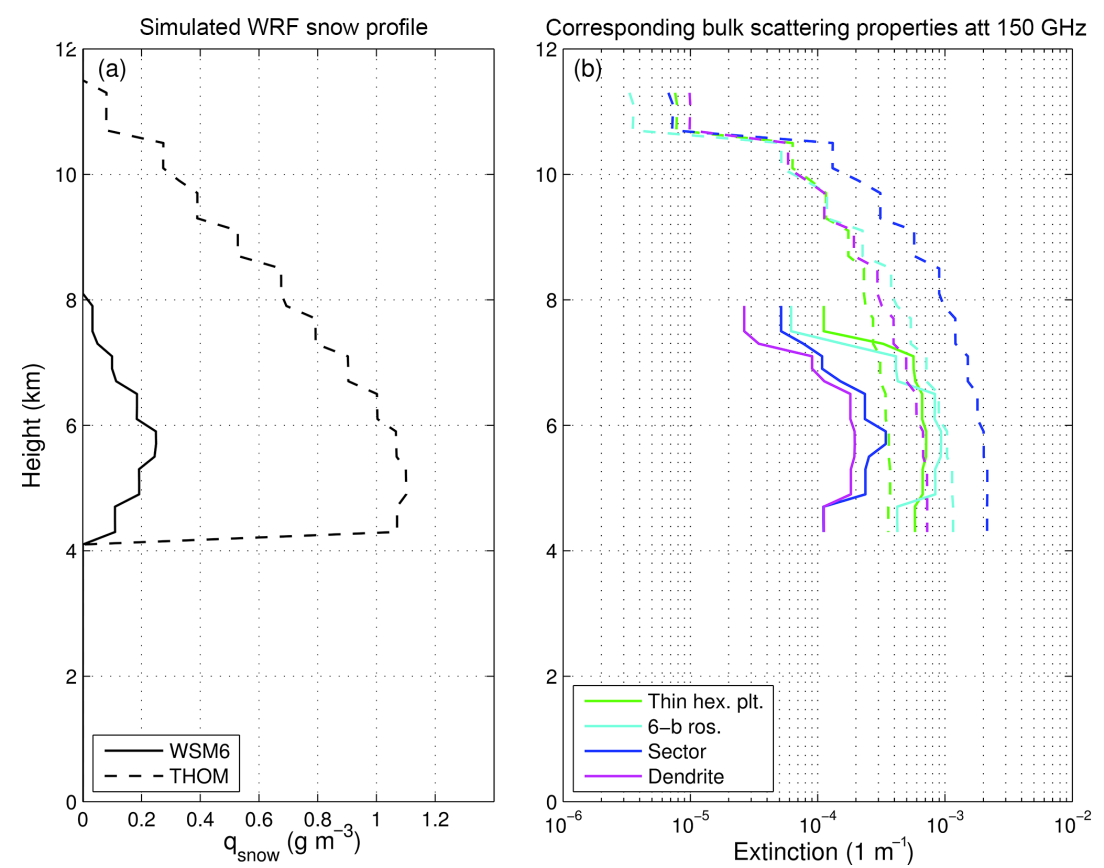

Figure 7. (a) The vertical profiles for the WSM6 and THOM snow mixing ratios $\left(\mathrm{g} \mathrm{m}^{-3}\right)$ for the corresponding pixel of maximum snow water path in an MHS transect explored in Sect. 4 and introduced in Fig. 4 i above. (b) The resultant vertical profile of the bulk scattering properties at $150 \mathrm{GHz}$ for the WSM6 (solid lines) and THOM (dashed lines) schemes, i.e. the extinction coefficient at each vertical level. The bulk optical properties have been computed at each vertical level by integrating the scattering properties of the equal mass Liu (2008) particle habits over the size distributions of interest.

pecially at the greater $D_{\max }$ values where the equal mass size approach starts to yields greater $D_{\max }^{\prime}$ values for the WSM6/WDM6 than the THOM scheme (i.e. greater scattering). Special attention needs to be made for the sector snowflakes, because as shown in Fig. 6c the WSM6/WDM6 and THOM normalized scattering cross sections are similar at large diameters. This is due to the maximum dimension of sector habits in the DDA database: $1 \mathrm{~cm}$. The WSM6/WDM6 $D_{\max }^{\prime}$ values are capped at this value. Figure $6 \mathrm{c}$ further shows that the thin hexagonal plates and six-bullet rosettes dominate at larger diameters, while at smaller diameters the sector habits are the most scattering. An analysis of the dependence of the scattering cross sections on frequency is shown to increase with frequency as expected (not shown). In order to further study the scattering properties with this approach to consistently simulate realistically the radiative properties of hydrometeors with WRF parameterizations, Fig. 7 shows the bulk scattering properties for a specific point of the transect introduced in Fig. 4i above. This is a transect of MHS observations that is discussed in Sect. 4 below. Figure 7a shows the vertical profiles for the WSM6 and THOM snow mixing ratios $\left(\mathrm{g} \mathrm{m}^{-3}\right)$ for the corresponding pixel of maximum snow water path in the transect. Figure $7 \mathrm{~b}$ shows the resultant vertical profile of the bulk scattering properties (e.g. the extinction coefficient $\beta_{\mathrm{e}}$ ) at $150 \mathrm{GHz}$ for the WSM6 (solid lines) and THOM (dashed lines) Field et al. (2005) snow particle size distributions, i.e. the extinction coefficient at each verti- cal level. This $\beta_{\mathrm{e}}$ parameter is calculated by integrating the extinction cross section $\sigma_{\mathrm{e}}(D)$ across the particle size distribution $N(D)$ at each vertical level:

$\beta_{\mathrm{e}}=\int_{0}^{\infty} \sigma_{\mathrm{e}}(D) N(D) \mathrm{d} D$.

The integrated bulk properties shown in Fig. $7 \mathrm{~b}$ include the effects of using the equal mass habit approach discussed above and the particle size distribution. Note that the WDM6 scheme is not shown as it has the same snow parameterizations as the WSM6. As expected, extinction (and scattering) increases with frequency (not shown) and snow water content. Not shown is the asymmetry parameter which gives an overall description of the phase function, i.e. the angular redistribution of scattered radiation. In contrast to the Liu (2008) habits, the low-density Mie sphere model (not shown) gives very strong forward scattering for high snow water content. The Liu (2008) habits produce more balanced forward and backward scattering. Although not shown graphically, analysing the sensitivity of these bulk scattering properties with frequency indicates that these conclusions are broadly true for the microwave range of interest in the present study. As the scattering increases, so do the differences between the bulk WSM6/WDM6 and THOM properties. Both the particle size distributions and how $D_{\max }^{\prime}$ differs from $D_{\max }$ play an important role. Figure $7 \mathrm{~b}$ illustrates the complex nature 
of evaluating the relative importance of these two effects. In the WSM6 scheme, the thin hexagonal plates and the sixbullet rosette are the most scattering habits, while the sector and the dendrite habits are the least scattering habits. For the THOM scheme, however, the sector habit is the most scattering. This is explained by the differences in the particle size distributions. The Field et al. (2005) snow particle size distribution has a greater number of smaller hydrometeors and a smaller number of larger hydrometeors than the WSM6/WDM6 snow particle size distribution. According to the analysis of Fig. 6c, the scattering cross sections behave differently for smaller and larger diameters. At larger diameters, the thin hexagonal plate is the most scattering habit, while at smaller diameters, the sector habit is the most scattering habit.

\section{Comparison of the simulations with coincident observations}

The objective of the following radiative transfer simulations is to consistently simulate the brightness temperature depressions observed related to the frozen phase using WRF microphysical properties and the necessary additional assumptions, with the aim of evaluating the different DDA habits and the WRF microphysics options for the meteorological event described in Sect. 2. It is not to simulate the detailed spatial structure of the observations because, as seen by comparing Figs. 2 and 4, there are differences in the location of the observed and modelled cloud system. This section proposes a sensitivity analysis of the compatibility of WRF outputs and its intrinsic microphysics parameterizations with the Liu (2008) DDA habits. The present study does not aim to search for the "best" Liu habit. As discussed in the previous sections, the radiative transfer simulations to be discussed depend mainly on (1) the integrated species content modelled by WRF, (2) the microphysics parameterized in each WRF scheme and (3) the additional single-scattering properties of the frozen phase, more specifically of snow species and graupel as discussed in Sect. 3. The particle size distribution remains consistent to the WRF microphysics scheme of interest, unless specified otherwise.

To focus on cloudy simulations, one must first achieve robust clear-sky simulations. For a quantitative comparison, the statistical distribution of the simulated and observed brightness temperatures is evaluated for some selected channels of TMI (10V, 19V, 22V, 37V, 85V GHz) and MHS (157, 89 and $183 \pm 1 \mathrm{GHz}$ ). The statistical distributions (not shown) show good agreement with the observed brightness temperatures under clear-sky conditions, confirming the reliability of the radiative transfer simulation inputs (e.g. the surface emissivity estimates used or the state of the atmosphere simulated by WRF). For the highly surface sensitive $19 \mathrm{GHz}$ channel and the water vapour sensitive $22 \mathrm{GHz}$ channel, good agreement is found for the WSM6, WDM6 and THOM schemes, with biases (observed-simulated) of approximately -3.55 and $0.6 \mathrm{~K}$ respectively over land. For the water vapour channel in MHS at $183 \pm 1 \mathrm{GHz}$, the schemes used show biases between -1.33 and $-1.68 \mathrm{~K}$ over land. The analysis of the distributions of simulated and observed brightness temperatures under both clear and cloudy conditions, especially in window channels, essentially shows that the largest differences between the observed and simulated brightness temperatures, and especially at higher frequencies, is located in the lower end of the brightness temperature histograms where scattering is important. Characterizing the scattering signal responsible for the largest brightness temperature differences is the focus of the present study.

Figure 8 shows the WSM6, WDM6 and THOM simulated brightness temperatures at $19 \mathrm{~V}, 37 \mathrm{~V}$ and $85 \mathrm{~V} \mathrm{GHz}$ for a specific TMI scan of the observations presented in Fig. 1 for 6 December at 07:00 UTC, at the initiation stages of the system. Figure 8 shows the brightness temperature simulations for the selected Liu (2008) DDA habits in Fig. 6. The bottom row of Fig. 8 shows the corresponding integrated snow, graupel and rain contents simulated by the different WRF schemes. The outermost right column shows the corresponding TMI observations and serves as a reference to analyse the simulations.

As discussed above, the clear-sky observations are well simulated by all schemes. However, the simulation of brightness temperatures in the presence of high snow and/or graupel contents is shown to be problematic. This is clearly evidenced in Fig. 8 by the large spread in the simulated brightness temperatures throughout the different schemes and the different DDA habits used. As expected, Fig. 8 shows that the higher the frequency, the larger the brightness depression simulated and the larger the sensitivity to the different DDA habits. The large sensitivity of the simulated BTs to the DDA habits shown in Fig. 8 illustrates how problematic the representation of snow/graupel scattering can be. Excessive scattering means that WRF generates more snow than is observed, that the radiative transfer model (and its necessary assumptions) simulates excessive scattering, or both.

At $10 \mathrm{GHz}$ (not shown), there is little sensitivity to scattering, and the most prominent feature is a strong brightness temperature drop at approximately $-32.9^{\circ}$ due to a lake in central Uruguay. This is observed more prominently in simulations and not in observations due to the simplified antenna pattern used in the simulations. Due to the lack of sensitivity to scattering, there is little sensitivity to the different DDA habits or WRF microphysics schemes at $10 \mathrm{GHz}$.

At $19 \mathrm{GHz}$, all DDA habits produce excessive scattering for the WSM6 and WDM6 simulations, where the dendrite and sector habits simulate the warmest BTs closest to the observed reference BTs, and the thick hexagonal plates and the block, long and short hexagonal columns (not shown) are the most scattering habits, producing the coldest BTs, followed by the thin hexagonal plate and the rosettes (only the sixbullet rosette is shown). On the other hand, all DDA habits 


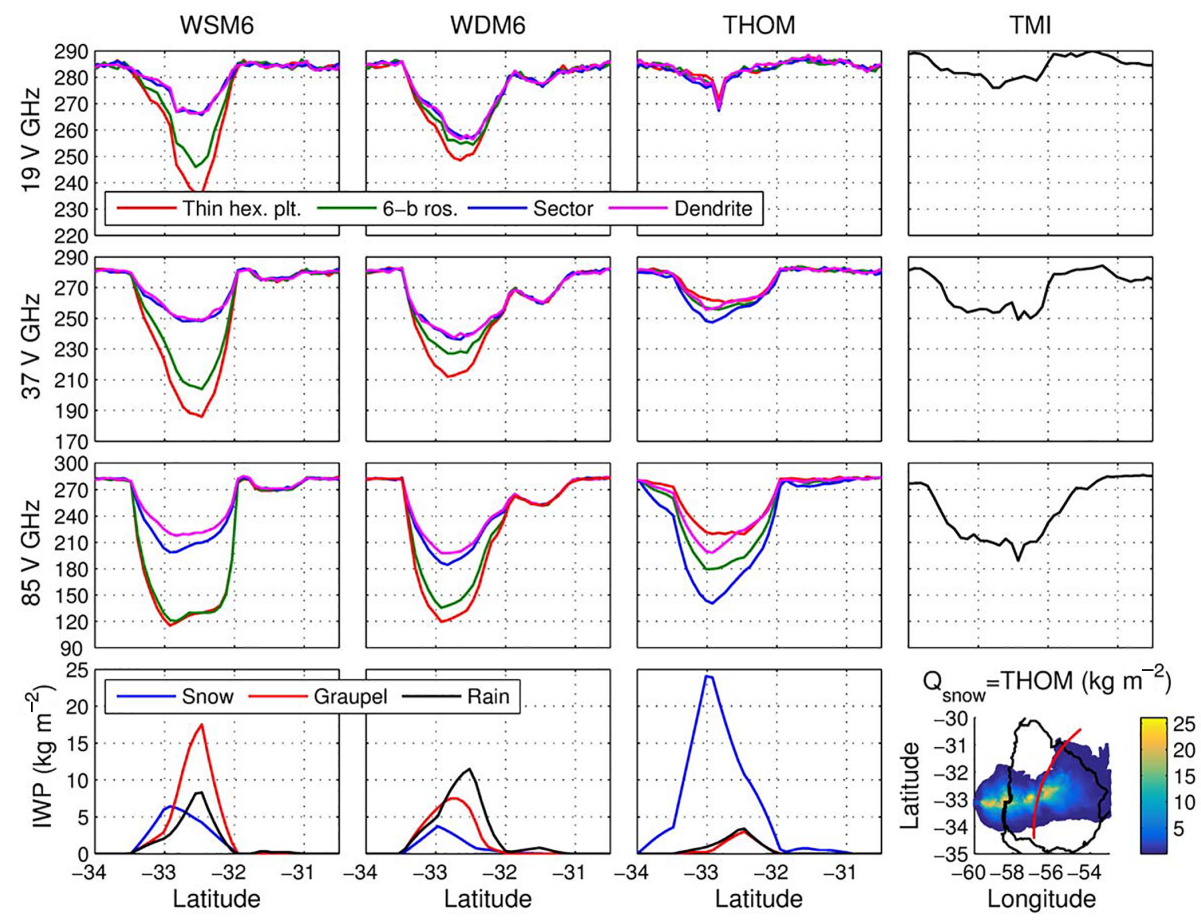

Figure 8. The simulated brightness temperatures for the TMI $19 \mathrm{~V}, 37 \mathrm{~V}, 85 \mathrm{~V} \mathrm{GHz}$ channels along a specific transect of interest shown in the bottom right panel, using selected Liu (2008) DDA habits (see legend) and the WSM6, WDM6 and THOM WRF schemes (the first three columns) and the observed brightness temperatures (in black in the last column). The corresponding integrated mass content of snow, graupel and rain are shown in the bottom row. Note that the bottom right panel shows the column-integrated WRF(THOM) snow mass content for the whole scene together with a solid red line to illustrate the location of the transect of interest.

in the THOM scheme simulations produce similar BT depressions to those observed. The large depression observed at $19 \mathrm{GHz}$ in the WSM6/WDM6 simulations is due to the high ice water path (IWP) frozen-phase content simulated by WRF. Simulations for the WSM6 show larger brightness depressions at $19 \mathrm{GHz}$ as they have a higher IWP graupel content. Note that simulations without the frozen phase show simulated brightness temperatures closer to those observed, but still show significant cold bias $(10 \mathrm{~K})$. Note that due to the small brightness temperature depressions simulated using the THOM scheme, the signal coming from the lake at approximately $-32.9^{\circ}$ can be observed at $19 \mathrm{GHz}$, while simulations using the WSM6/WDM6 schemes are dominated by excessive scattering and consequently frozen-phase scattering cloud signals dominate all surface signals. Note that although the THOM scheme is predicting the greatest amount of integrated snow content, it does not necessarily produce the largest brightness temperature depressions.

Similar conclusions can be drawn for the $37 \mathrm{GHz}$ simulations. At $37 \mathrm{GHz}$, however, as expected, the sensitivity to scattering increases and consequently BT depressions also increase. All habits, except the sector and dendrite habits, produced excessive scattering with the WSM6 and the WDM6 schemes. Under the WDM6 scheme simulations, DDA habits show warmer BTs compared to the
WSM6 scheme. This is due to the strong graupel content simulated by the WSM6 scheme. In the WSM6 and WDM6 schemes, sector and dendrite habits simulate comparable BTs to those observed, while the thick hexagonal plates and the block, long and short hexagonal columns (not shown) are the most scattering habits, producing larger BT depressions than those observed, followed by the thin hexagonal plate and the rosettes (only the six-bullet rosette is shown). For the THOM scheme simulations, the DDA habits show a smaller spread in simulated BTs, and these BTs are all comparable to the reference observations, except for the three-, four- and five-bullet rosettes (not shown) and the sector habit.

Simulations at $85 \mathrm{GHz}$, as expected, show an even higher sensitivity to scattering. In general, the combination of WSM6, WDM6 and the DDA habits analysed follow the same sensitivities because they have the same particle size distribution, the same snow and graupel density $(0.1$ and $0.4 \mathrm{~kg} \mathrm{~m}^{-3}$ ) and similar snow and graupel column contents. In these schemes, and for all the frequencies analysed, the sector and dendrite habits scatter the least and produce BT depressions closest to the reference TMI observations. The thick hexagonal plates and the long, short and block hexagonal columns (not shown) scatter the most, followed by the thin hexagonal plate and rosettes (only the six-bullet rosette is shown). These produce excessive scattering in comparison 


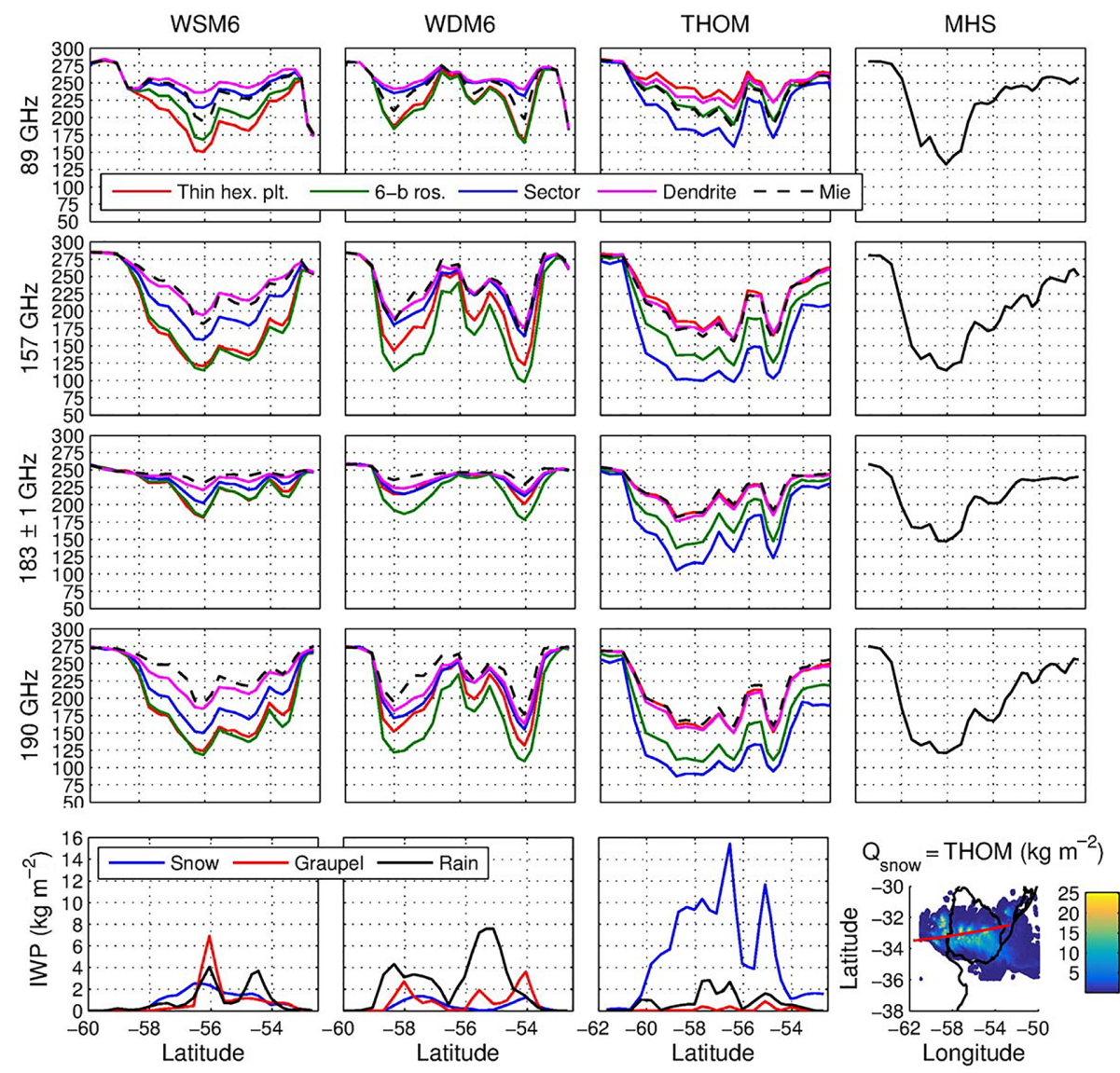

Figure 9. Similarly to Fig. 7, the simulated brightness temperatures for the $89,157,183 \pm 1$ and $190 \mathrm{GHz}$ MHS channels along the transect of interest shown in Fig. 4i using a selection of Liu (2008) DDA habits and the soft-sphere Mie approach and the WSM6, WDM6 and THOM WRF schemes (in the first three columns). The last column shows reference MHS observations for the transect in solid black lines. The corresponding integrated mass content of snow, graupel and rain are shown in the bottom row. Note that the bottom right panel shows the column-integrated WRF(THOM) snow mass content for the whole scene together with a solid red line to illustrate the location of the transect of interest.

to the reference observations. As discussed in Sect. 3, the bulk DDA(THOM) scattering properties are different than the bulk DDA(WSM6/WDM6) scattering properties due to the different particle size distributions and mass-size relationships (see discussion in Sect. 3). This is illustrated in Fig. 8 for the $85 \mathrm{GHz}$ channel simulations. For the THOM scheme simulations, contrary to the WSM6 and WDM6 simulations, the thin hexagonal plate simulates the warmer BTs (smallest BT depressions), while the sector habits produce the coldest temperatures (largest BT depressions). Note that simulations without the frozen phase, similarly to the $19 \mathrm{GHz}$ simulations discussed above, have also been conducted at 37 and $85 \mathrm{GHz}$. These simulations show that, as expected, as the frequency increases, the relative contribution of the frozen phase increases. At 37 and $85 \mathrm{GHz}$, the difference between simulations with and without the frozen phase were shown to be 10 and $60 \mathrm{~K}$ respectively.

MHS simulations at higher frequencies provide higher sensitivity to the scattering properties. Figure 9, similarly to
Fig. 10, focuses on a specific MHS scan from close to nadir to its outermost angle east, characterized by high snow content in the WRF simulations (see black line Fig. 4g). This transect belongs to observations on 6 December at 17:00 UTC shown in Fig. 2, where the system is in its developed stage. Figure 9 shows the simulated brightness temperatures of MHS channels with the exception of $183 \pm 3 \mathrm{GHz}$, as it is very similar to $183 \pm 1 \mathrm{GHz}$ due to its water vapour sensitivity, for the WSM6, WDM6 and THOM schemes. The bottom row of Fig. 9 shows the corresponding integrated snow, graupel and rain contents simulated by the different WRF schemes and the outmost right column shows the corresponding reference MHS observations. MHS observations must be used as a reference and not as a direct comparison to the simulations due to differences in timing and spatial structure of the meteorological fields modelled by WRF.

As expected the higher the frequency window channel, the largest the brightness temperature depressions. As analysed for the TMI transect, Fig. 9 shows that for WSM6 and 


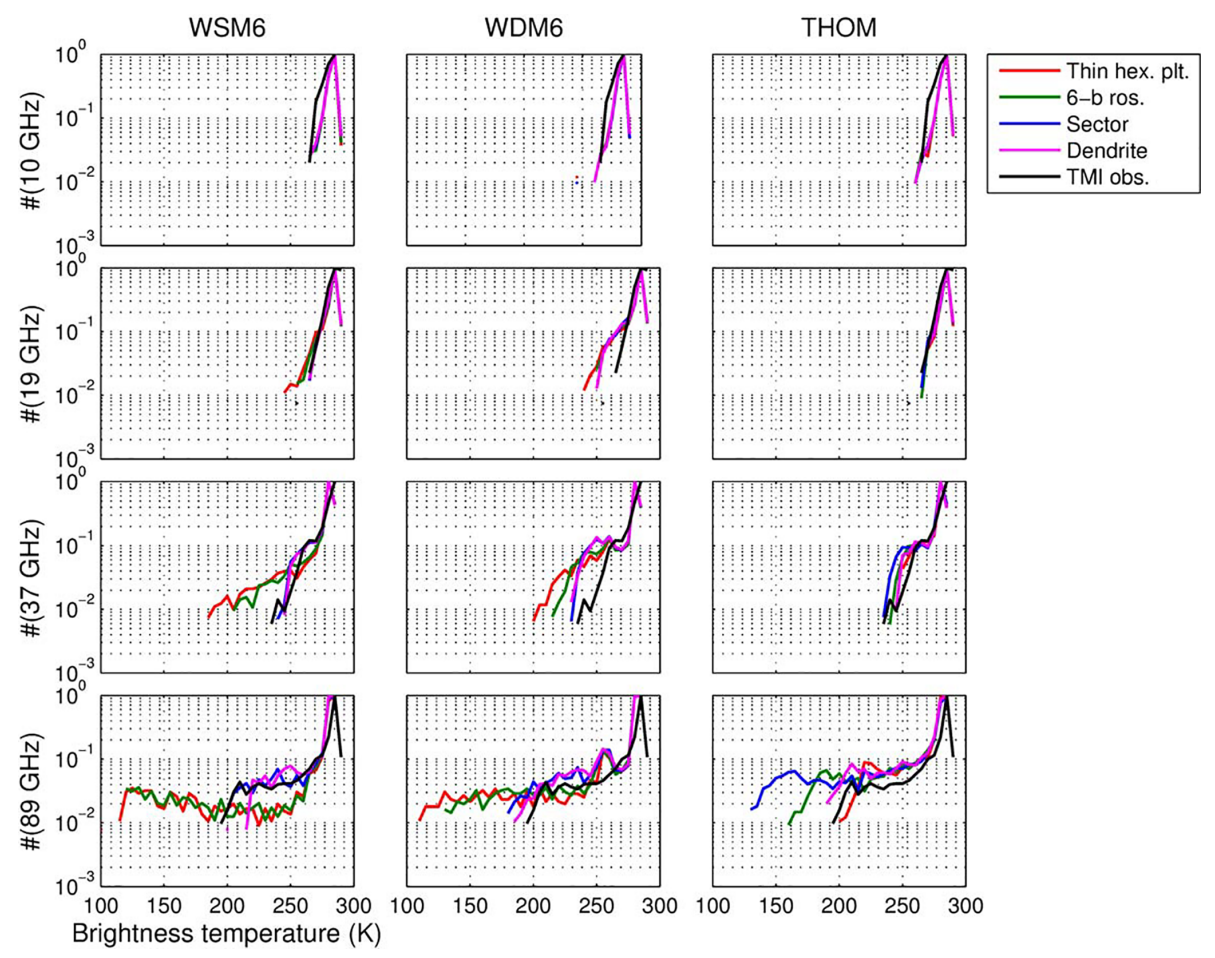

Figure 10. The observed (solid black line) and simulated (solid coloured lines) TMI brightness temperature distributions (built with $5 \mathrm{~K}$ bins and where bins with less than five values are neglected).

WDM6 simulations, the dendrite and sector habits are the least scattering habits, and for simulations with the THOM scheme, the dendrite and the thin hexagonal plates (and the thick hexagonal plates and the long, short and block hexagonal columns not shown), are the least scattering habits. The habits producing the largest brightness temperature depressions in the WSM6 and WDM6 schemes are the thick hexagonal plates and the long, short and block hexagonal columns (not shown), followed by the thin hexagonal plate and the rosettes (only the six-bullet rosette is shown), as discussed for the TMI channels simulated. In the THOM scheme, the coldest BTs are observed for the sector habits and the thin hexagonal plates as shown in Fig. 9, and the thick hexagonal plates and the long, short and block hexagonal columns (not shown), also as discussed for the TMI channels.

As shown in Fig. 8 for the TMI simulations, the THOM scheme MHS simulations in Fig. 9 show that, in contrast to the WSM6 and WDM6 scheme simulations, the thin hexagonal plate produces the smallest brightness temperature depressions and the sector habit produces the largest brightness temperature depressions. This is a result of the equal mass approach and the schemes' particle size distributions.

Note that simulations using the soft sphere approximation and with a Mie theory with the corresponding WRF microphysics parameterized densities are included in Fig. 9 (black dashed lines). The behaviour of the Mie sphere simulations compared with those of the DDA habits is very different with frequency, and are not scattering enough at high frequencies. Following Liu (2004), Mie theory can be used to reproduce the ensemble of the DDA database by adjusting the air fraction with frequency. This approach hence has no physical basis. It can be argued, however, that choosing one of the Liu habits to represent the highly complex and variable habit population is also problematic.

Figures 10 and 11 show a quantitative comparison of the simulated and observed brightness temperature distributions for the whole meteorological scene simulated for relevant TMI and MHS observations respectively. The statistical distributions of the brightness temperatures are shown for the observations (black line) and radiative transfer simulations of a selected group of DDA habits (coloured lines consistent with Figs. 6-9). Note that only data over land, i.e. excluding coastal data and data over the ocean, are accounted for in these distributions which are built with $5 \mathrm{~K}$ bins and where bins with less than five values are neglected.

As expected, Figs. 10 and 11 show that most departures between observations and simulations are associated with cloudy situations at low brightness temperatures. Figure 10 shows that, as expected, simulations at $10 \mathrm{GHz}$ show little sensitivity to scattering. At the higher $19 \mathrm{GHz}$ channel, the simulations start to show a larger sensitivity to the DDA habits. The simulations using the WDM6 scheme lead to excessive scattering at 19 and $37 \mathrm{GHz}$ for all the habits shown. For the simulations with the WSM6 scheme, the thin hexag- 

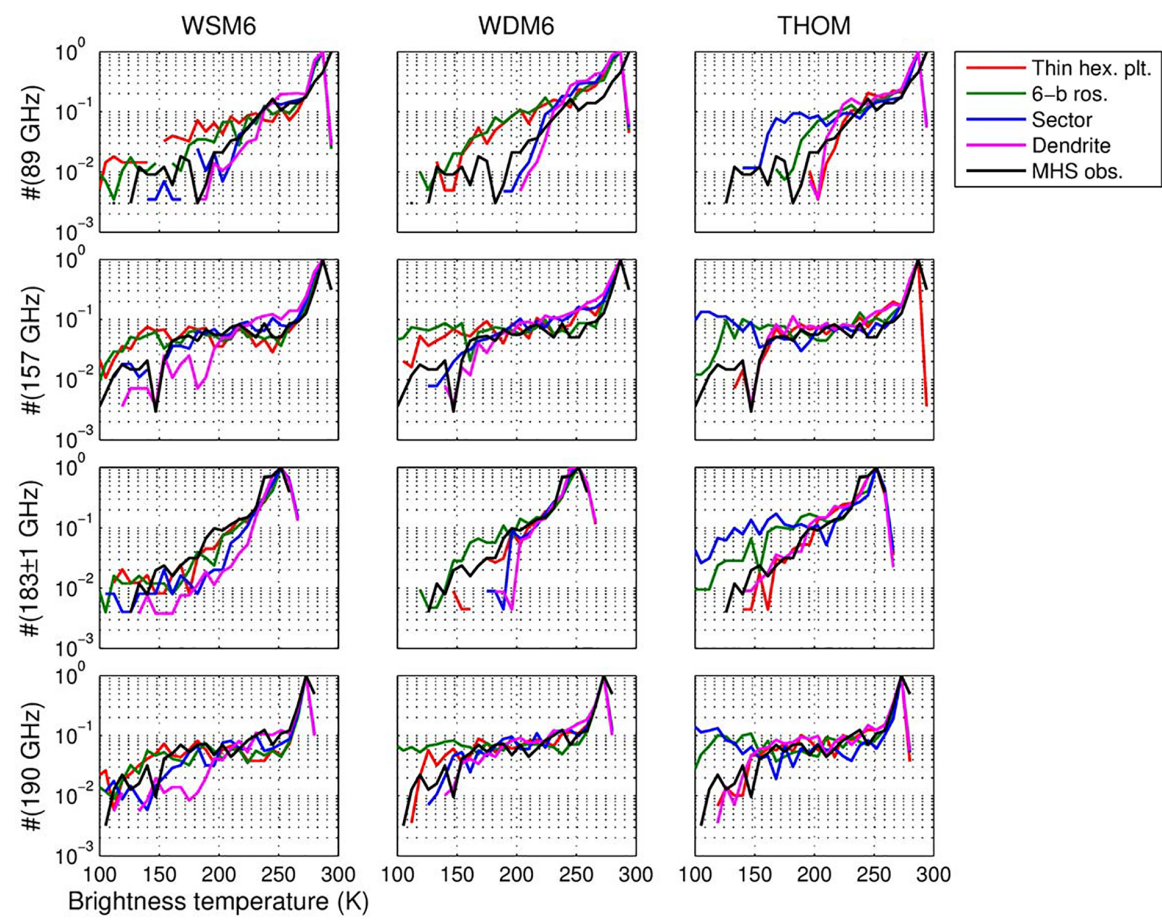

Figure 11. The observed (solid black line) and simulated (solid coloured lines) MHS brightness temperature distributions (built with $5 \mathrm{~K}$ bins and where bins with less than five values are neglected).

onal plate and the six-bullet rosette show excessive scattering in comparison to observations at 37 and $89 \mathrm{GHz}$, while the sector and dendrite habits show a comparable distribution with those observed. Finally, simulations with the THOM scheme show comparable distributions to those observed for all DDA habits up to $37 \mathrm{GHz}$, while at $89 \mathrm{GHz}$, the thin hexagonal plate and the dendrite habits behave similarly to the observations. Figure 11 shows further information to analyse the sensitivity to the choice of DDA habits using the higher-frequency channels onboard MHS. Similarly to Fig. 10, simulations with the WDM6/WSM6 scheme, and the thin hexagonal plate or the six-bullet rosette show excessive scattering especially for the 89 and $157 \mathrm{GHz}$ MHS frequency channels, while the sector habit produces a BT distribution closest to the observed distribution. Finally, the simulations with the THOM scheme show that the sector and six-bullet rosette produce excessive scattering, while the dendrite and thin hexagonal plate produce distributions closest to those observed. In general for the scene analysed, the dendrite habit performs best for all the schemes. Similar results were obtained by Geer and Baordo (2014) when analysing the DDA shapes over land.

With the aim of analysing quantitatively the behaviour of the different DDA habits under the three different microphysics schemes, the $\chi^{2}$ test is used. The $\chi^{2}$ test is a verification method to evaluate how close the simulated distributions are to the observed distributions. Figures 12 and 13 show the relative residuals $E_{i}$ computed for each bin following

$$
E_{i}=[X(i)-Y(i)] / \sqrt{X(i)},
$$

where $X(i)$ and $Y(i)$ are the relative frequencies of observations and simulations respectively for the $i$ th bin of the TMI and MHS observations respectively. The histograms and the $\chi^{2}=\sum E_{i}^{2}$ values shown only take into account bins below $270 \mathrm{~K}(250 \mathrm{~K}$ for $183 \pm 1 \mathrm{GHz})$ in order to neglect clear-sky pixels and focus on the cloudy contribution. Figures 12 and 13 further aid the analysis of Figs. 10 and 11 by showing the performance of the simulations using the different DDA habits with the different microphysics schemes. The dendrite habits show low $\chi^{2}$ value across the microphysics schemes. In the WSM6 and WDM6 schemes, the sector snowflakes also perform well. The sector snowflakes, however, show very high $\chi^{2}$ values in the THOM scheme simulations. In the THOM scheme simulations, the thin hexagonal plates follow the dendrite habits in the low $\chi^{2}$ values.

Finally, Fig. 14 (Fig. 15) shows TMI (MHS) observations in the first column, followed by the radiative transfer simulations using the dendrite habits to describe the scattering properties in the WSM6, WDM6 and THOM schemes (second, third and fourth columns respectively). Despite errors in the location and coverage of the spatial structures of the cloudy fields modelled by WRF, the results depicted show that the three WRF microphysics schemes can be used to simulate the observed brightness temperature depressions provided special care is taken to represent the scattering properties of the 

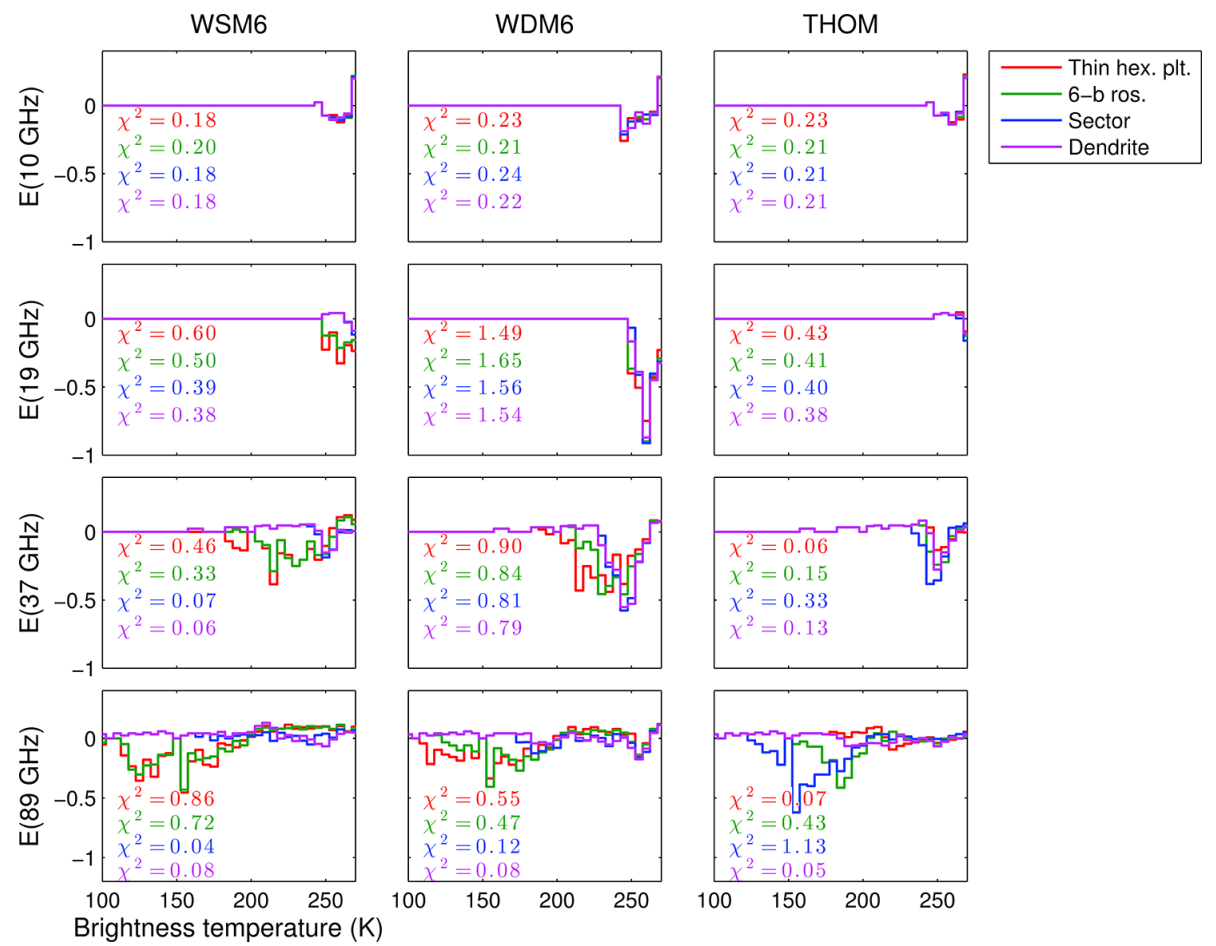

Figure 12. The simulated (solid coloured lines) residuals of the $\chi^{2}$ test for the TMI brightness temperature distributions. Note that the $\chi^{2}$ value is included for each of the DDA habit simulated distributions calculated from all temperature bins below $270 \mathrm{~K}$.
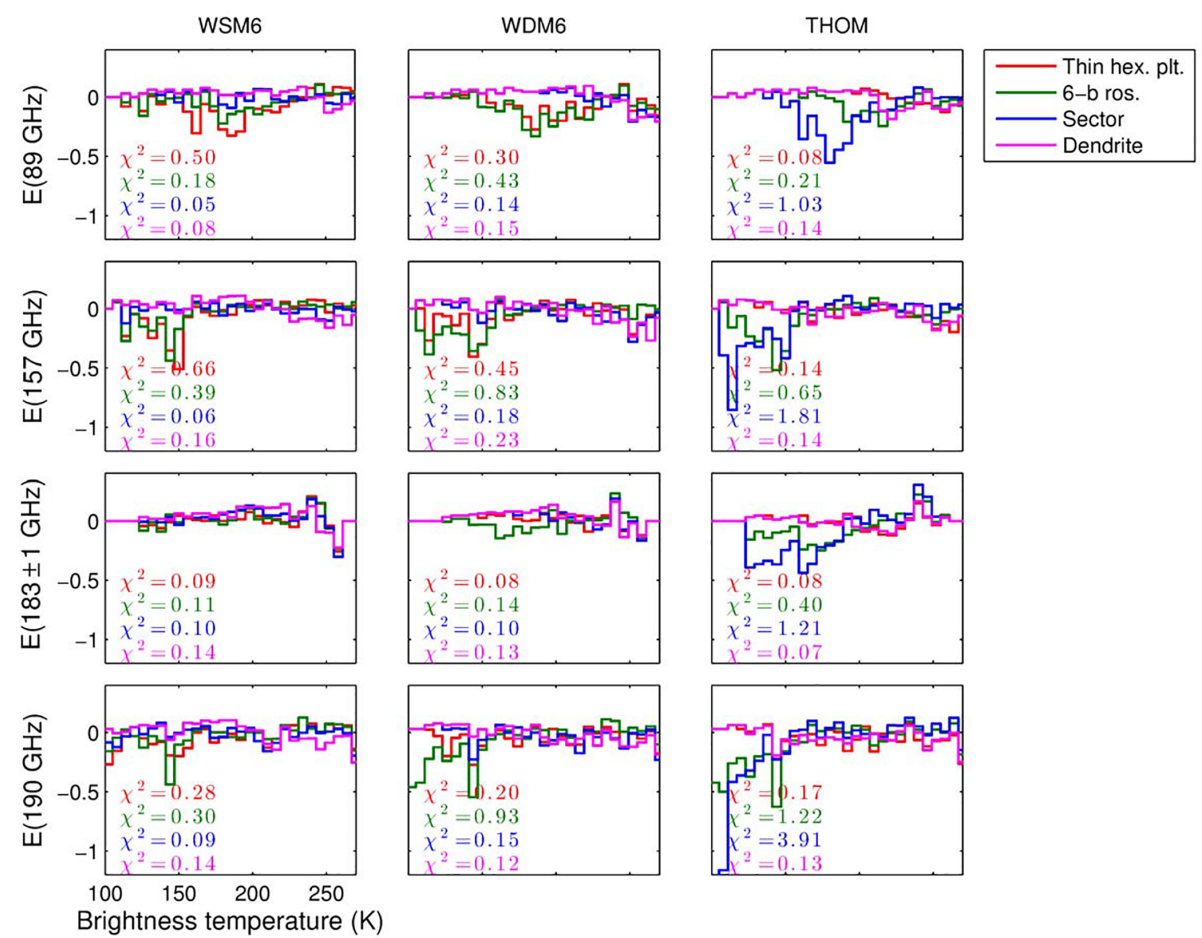

Figure 13. The simulated (solid coloured lines) residuals of the $\chi^{2}$ test for the MHS brightness temperature distributions. Note that the $\chi^{2}$ value is included for each of the DDA habit simulated distributions calculated from all temperature bins below $270 \mathrm{~K}(250 \mathrm{~K}$ for the $183 \pm 1 \mathrm{GHz}$ channel). 

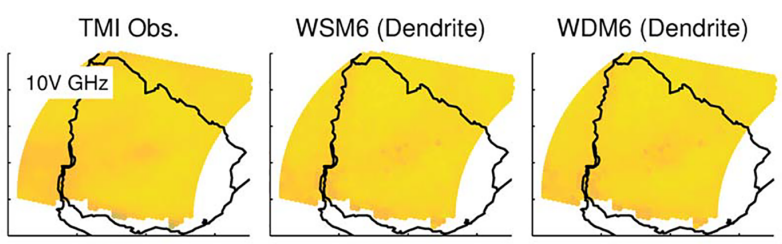

THOM (Dendrite)
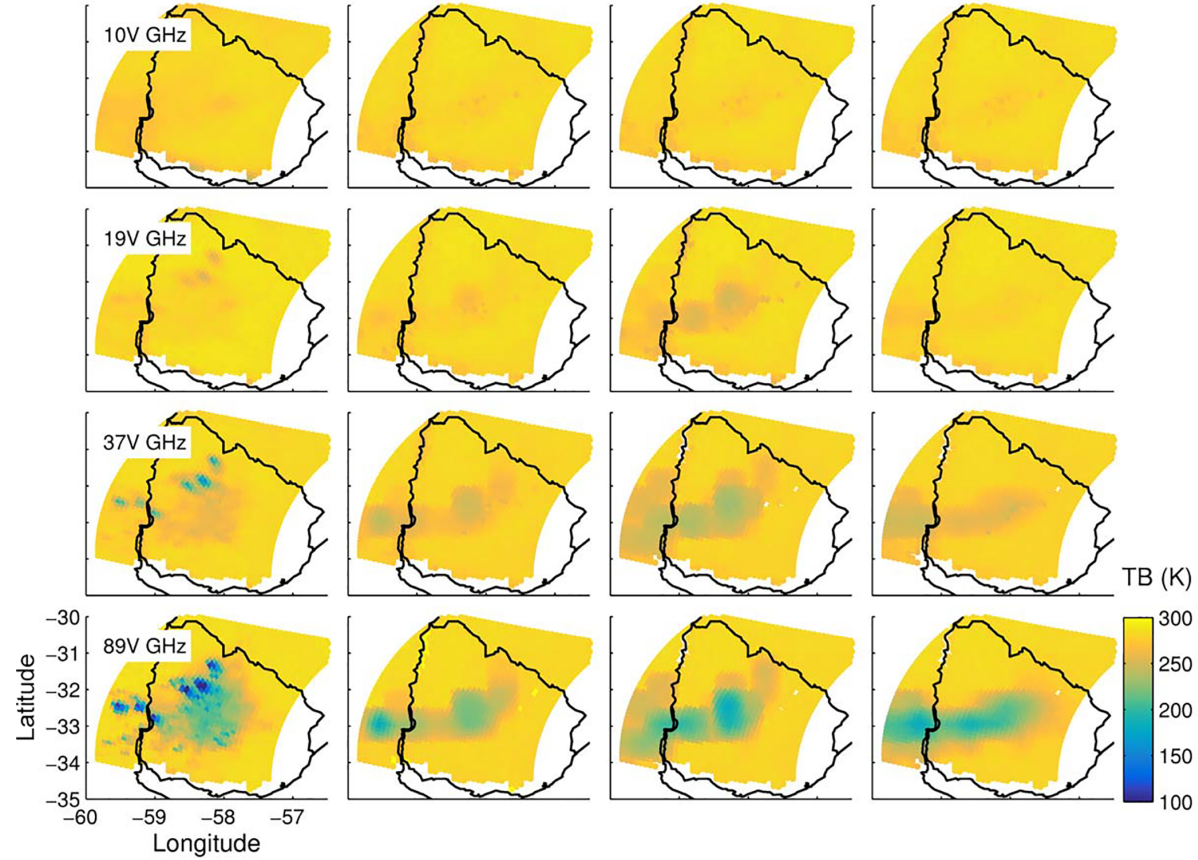

Figure 14. TMI observations at $10 \mathrm{~V}, 19 \mathrm{~V}, 37 \mathrm{~V}$ and $89 \mathrm{~V} \mathrm{GHz}$ (first column), as compared to the corresponding radiative transfer simulations using the dendrite habits for the WSM6, WDM6 and THOM scheme simulations.

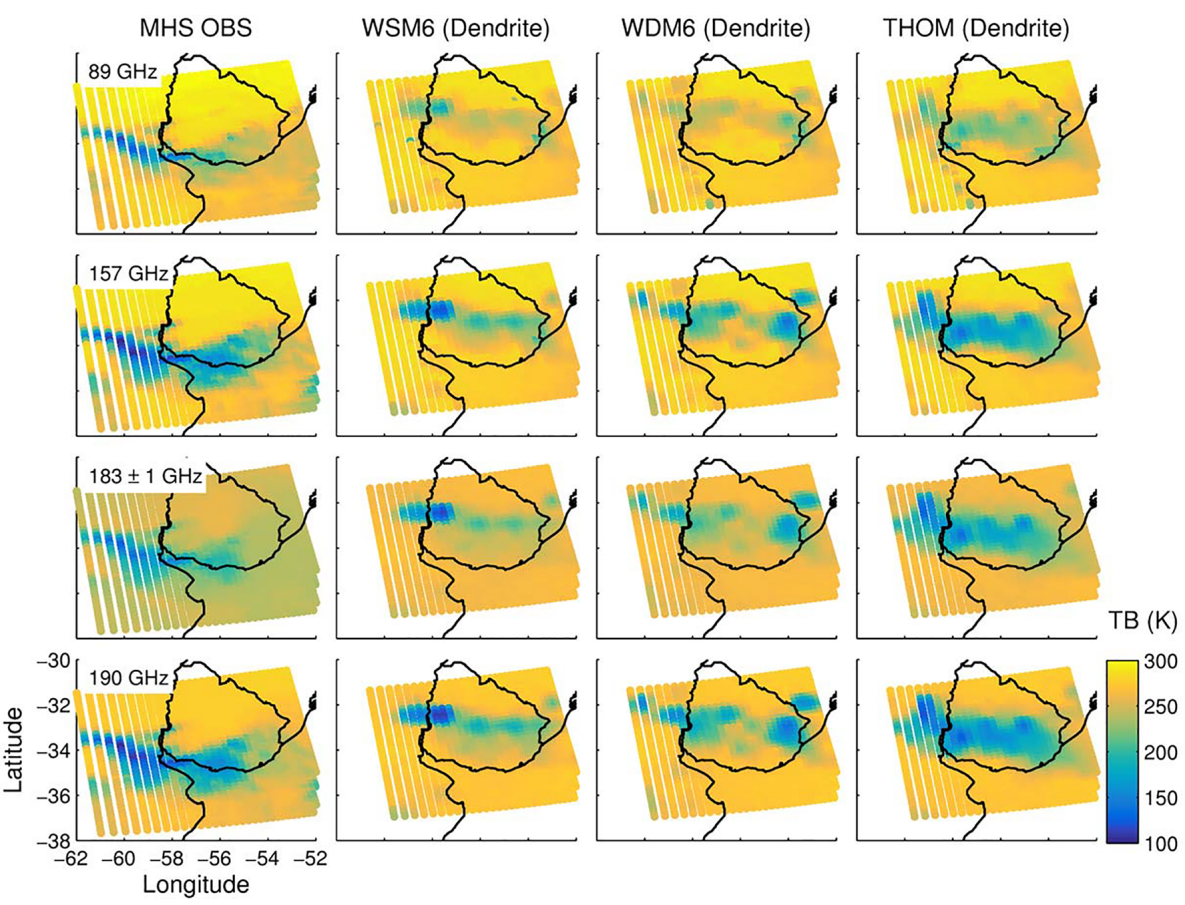

Figure 15. MHS observations at $89,157,183 \pm 1$ and $190 \mathrm{GHz}$, as compared to the corresponding radiative transfer simulations using the dendrite habits for the WSM6, WDM6 and THOM scheme simulations. 


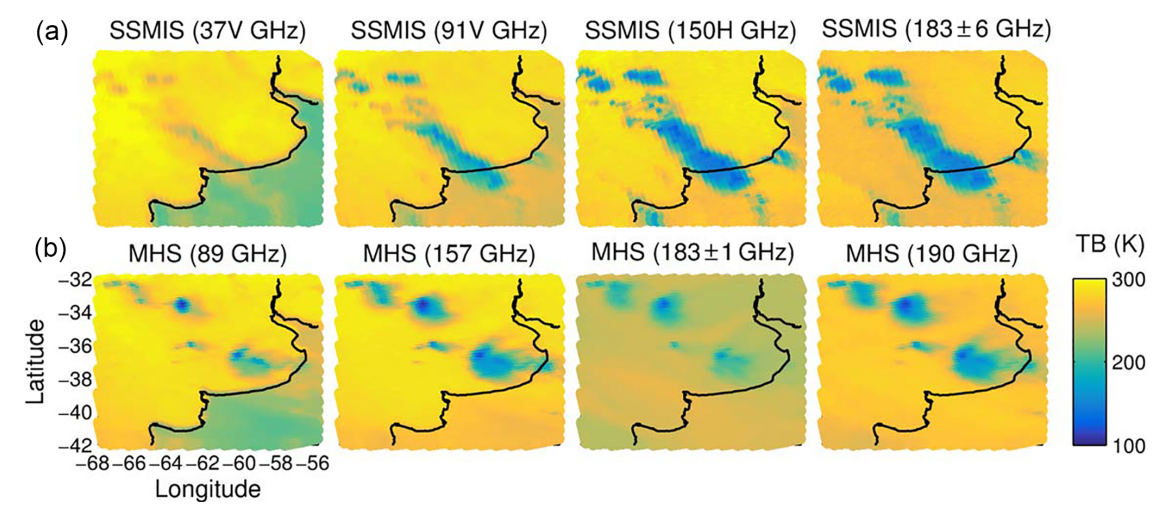

Figure 16. Coincident microwave observations for two MCS events of interest. (a) Observed brightness temperatures for selected SSMI/S channels over south-eastern South America on 13 January 2011 at 22:00 UTC. (b) Observed brightness temperatures for selected MHS channels over south-eastern South America on 23 January 2014 at 02:00 UTC.

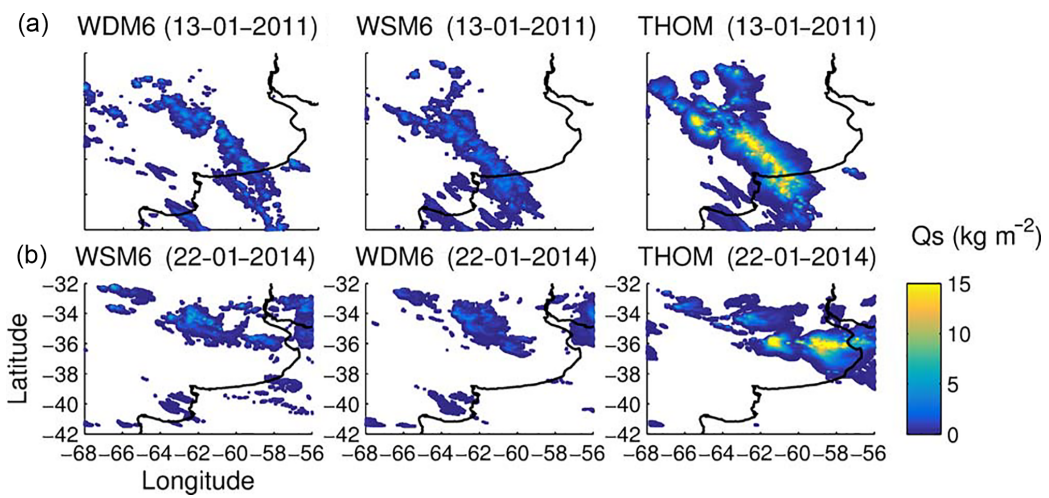

Figure 17. The integrated column content in $\mathrm{kg} \mathrm{m}^{-2}$ for snow as simulated by the WRF microphysics options WSM6, WDM6 and THOM, on 13 January 2011 at 22:00 UTC (a) and on 23 January 2014 at 02:00 UTC (b), with a $0.05 \mathrm{~kg} \mathrm{~m}^{-2}$ minimum threshold

snow and graupel species. At $19 \mathrm{GHz}$, the THOM scheme does not have deep enough brightness temperature depressions as observed, while at $37 \mathrm{GHz}$, the WDM6 scheme is the only model to generate brightness temperature depressions as low as observed, albeit over a wider area than observed. At $89 \mathrm{GHz}$, none of the schemes reach deep enough brightness temperature depressions as observed. MHS simulations have a higher sensitivity to frozen scattering. Figure 15 shows good agreement between the three microphysics schemes and MHS observations. The THOM scheme, however, has a broader spread of BT depressions, versus the too-narrow areas of BT depression from the other schemes. Similarly to Fig. 14, Fig. 15 also shows that at $89 \mathrm{GHz}$ none of the schemes reach deep enough brightness temperature depressions as observed.

\section{Extending the radiative transfer simulations to two additional MCS events of interest}

Two additional convective events in south-eastern South America are analysed in this section in order to further test the validity of the conclusions drawn above. The two events are observed over central Argentina on 13 January 2011 and 23 January 2014, and microwave observations are available from the Special Sensor Microwave Imager/Sounder (SSMI/S) at 22:00 UTC and MHS at 02:00 UTC respectively. These observations are shown for the most scattering sensitive channels in the first and second rows of Fig. 16 for SSMI/S and MHS for a relevant selection of instrument channels.

Figure 17 shows the integrated column content in $\mathrm{kg} \mathrm{m}^{-2}$ with a minimum threshold of $0.05 \mathrm{~kg} \mathrm{~m}^{-2}$, simulated by WRF for these two scenes at the time of the available coincident observations. Figure 17 shows the strong sensitivity of the hydrometeor content to the WRF microphysical parameterizations, as discussed in Sect. 2.2. Similarly to the WRF simulations analysed in Sect. 2.2, Fig. 17 shows that the WSM6 and the WDM6 schemes model similar hydrometeor mass loadings for the iced species (i.e. snow, graupel and ice, not all shown), while the THOM scheme shows much higher snow content. Similarly to the scene analysed in the previous section, the WSM6 simulates the highest graupel content (not shown) followed by the WDM6 scheme. The THOM scheme 


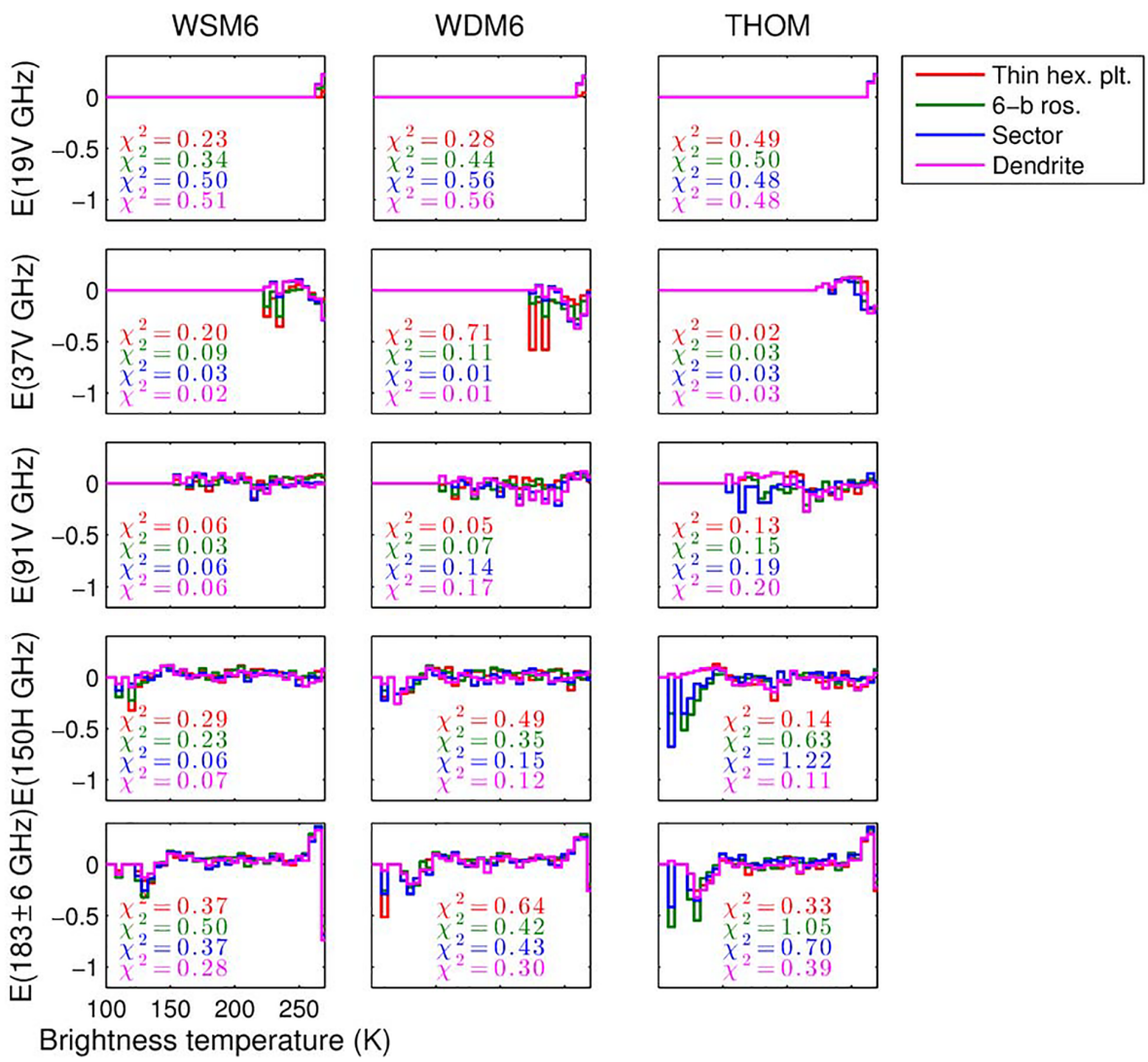

Figure 18. The simulated (solid coloured lines) residuals of the $\chi^{2}$ test for the simulated SSMI/S $19 \mathrm{~V}, 37 \mathrm{~V}, 91 \mathrm{~V}, 150 \mathrm{H}$ and $183 \pm 6 \mathrm{GHz}$ channels for the MCS events on 13 January 2011 at 22:00 UTC. Note that the $\chi^{2}$ value is included for selected DDA habit simulated distributions calculated from all temperature bins below $270 \mathrm{~K}$.
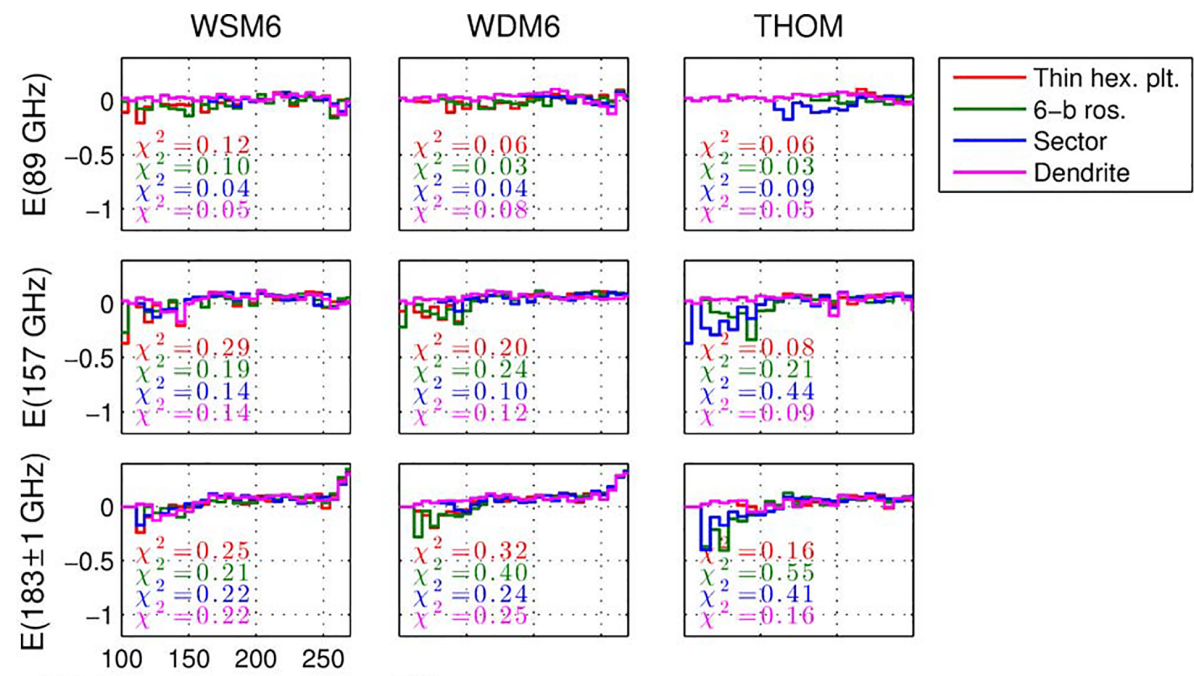

Brightness temperatures $(\mathrm{K})$

Figure 19. The simulated (solid coloured lines) residuals of the $\chi^{2}$ test for the simulated MHS 89,157 and $183 \pm 1 \mathrm{GHz}$ channels for the MCS events on 13 January 2011 at 22:00 UTC. Note that the $\chi^{2}$ value is included for selected DDA habit simulated distributions calculated from all temperature bins below 270 and $250 \mathrm{~K}$ for the $183 \pm 1 \mathrm{GHz}$ channel). 


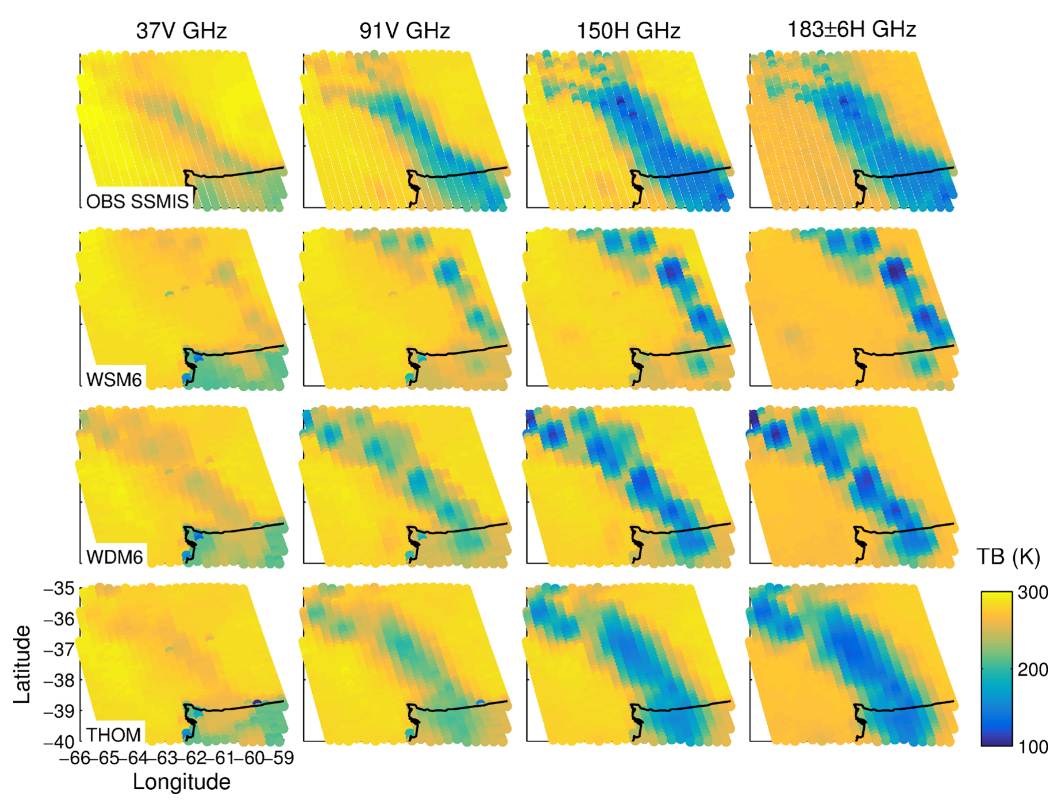

Figure 20. SSMI/S observations, as compared to the corresponding radiative transfer simulations using the dendrite habits for the WSM6, WDM6 and THOM scheme simulations for the 13 January 2011 event analysed.

produces very little graupel content. Note that the two scenes analysed in this section are comparable in IWPs with the case analysed in Sect. 4. Similarly to Sect. 3, it can also be seen from Figs. 16 and 17 that the microphysics schemes in WRF model the structure and location of the cloudy system fairly well for these two scenes too.

Radiative transfer simulations are performed for these two scenes in the same manner as described in Sect. 3, and the histograms of the simulated and observed brightness temperatures for the two scenes (not shown) are analysed. Analysing the scene on 13 January 2011 which has coincident SSMI/S observations, it can be shown that at $19 \mathrm{GHz}$, the radiative transfer simulations using all the DDA habits with the WSM6, WDM6 and THOM schemes result in similar BTs. Unlike the scene analysed in Sect. 4, the WDM6 scheme in this scene does not show excessive scattering at $19 \mathrm{GHz}$. At $37 \mathrm{GHz}$, however, the WDM6 simulations show a pronounced large population of simulations with brightness temperatures between 250 and $270 \mathrm{~K}$ for all habits. At $37 \mathrm{GHz}$, the WDM6 scheme simulations show that the thin hexagonal plates and the six-bullet rosettes have the coldest brightness temperatures (largest BT depressions). These BT depressions are unrealistically large compared to the coincident observations. In the WSM6 simulations, similarly to Sect. 4, the thin hexagonal plate and the six-bullet rosette habits are responsible for the coldest brightness temperatures, while the dendrite and sector snowflakes have warmer BTs and are closer to the observed brightness temperatures. The simulated THOM scheme brightness temperatures, on the other hand, show that all DDA habit simulations produce
BTs that are very close to the observed BT distributions, as discussed for the simulations in Sect. 4.

For frequencies above $37 \mathrm{GHz}$, i.e. $91 \mathrm{~V}, 150 \mathrm{H}$ and $183 \pm 6 \mathrm{H} \mathrm{GHz}$, since there is a larger sensitivity to scattering, there is a larger sensitivity to the different habits. To aid this discussion, the relative residuals $E_{i}$ are computed for this histograms in the same way as described in Sect. 4, and their $\chi^{2}$ values shown in Fig. 18. As shown in Sect. 4, the THOM scheme simulations with the thin hexagonal plate and the dendrite habits show the smallest $\chi^{2}$ values, while in the WSM6/WDM6 the dendrite and sector snowflakes show the smallest $\chi^{2}$ values. Similar conclusions are drawn for the scene with available coincident MHS observations, where the corresponding residuals and $\chi^{2}$ values calculated from the histograms of the brightness temperatures are shown in Fig. 19. Note that only the most sensitive channels to scattering are shown, i.e. 89, 157 and $190 \mathrm{GHz}$.

Finally, Figs. 20 and 21 show that, as discussed for the MCS event simulated and analysed in Sect. 4, radiative transfer simulations using the WSM6 and the THOM microphysics schemes can be used to simulate the observed brightness temperature depressions using the dendrite DDA habits to represent the scattering properties of the snow and graupel species. In this scene, as discussed above, the WDM6 is shown to produce warmer brightness temperatures than observed at MHS channels.

\section{Conclusion}

Three meteorological events of extreme deep moist convection, characteristic of south-eastern South America, have 


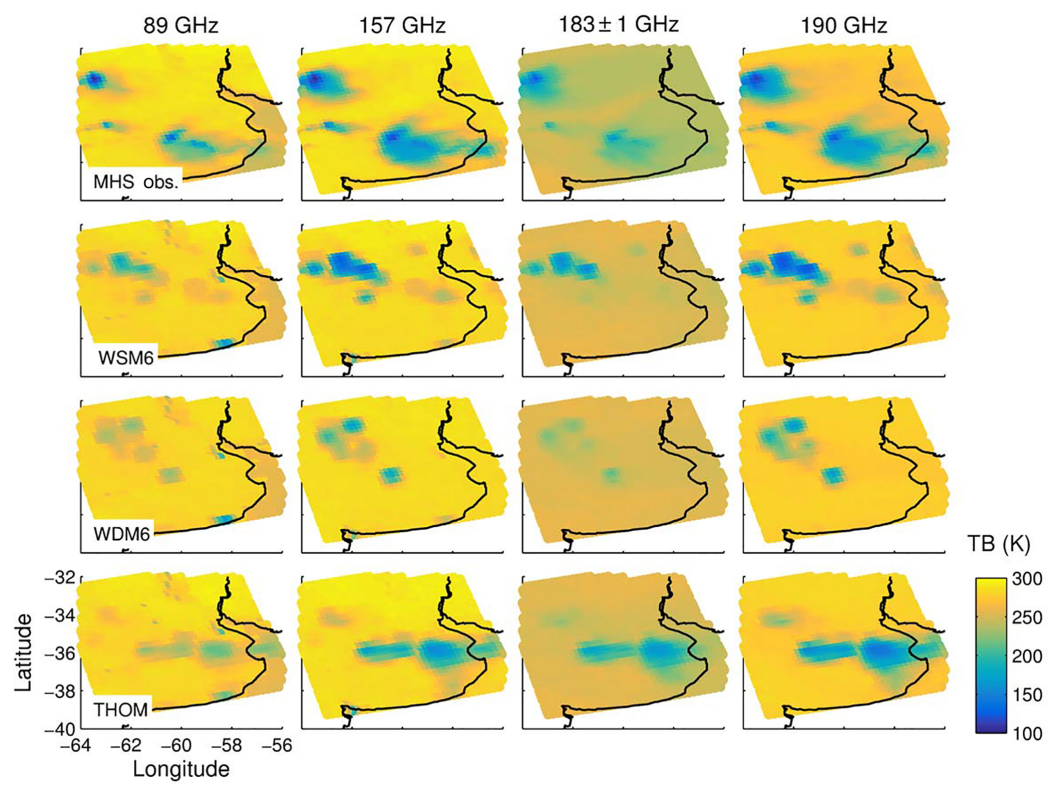

Figure 21. MHS observations, as compared to the corresponding radiative transfer simulations using the dendrite habits for the WSM6, WDM6 and THOM scheme simulations for the 23 January 2014 event analysed.

been considered in the present study to conduct a direct comparison between satellite-based simulated and observed microwave radiances, and to evaluate three different WRF microphysical schemes. In order to do this, a research radiative transfer model, ARTS, has been coupled with the WRF model under the WSM6, WDM6 and THOM microphysical parameterizations. Since the simulation of passive microwave radiances requires good knowledge of the scattering properties of frozen hydrometeors, the present study has further aimed at improving the understanding of frozen hydrometeor optical properties and the characteristics of deep convection in the SESA region. Bulk optical properties are computed by integrating the single-scattering properties of particles across a given particle size distribution. While the particle size distribution of species is intrinsic to each WRF microphysics scheme, cloud resolving models like WRF do not determine all of the parameters needed to determine the single-scattering properties, and further assumptions are necessary. In this study the Liu (2008) DDA single-scattering database, with 11 different iced habits, has been used to provide realistic scattering properties for snow and graupel species. In order to apply the optical properties of the Liu (2008) DDA database to the hydrometeor species modelled by the WRF microphysics schemes in a consistent manner, the equal mass approach is introduced. The equal mass approach consists of describing the optical properties of the WRF snow and graupel hydrometeors with the optical properties of habits in the DDA database whose dimensions might be different $\left(D_{\max }^{\prime}\right)$ but whose mass is conserved. The performance of the radiative transfer simulations have been evaluated by comparing the simulations with the available coincident microwave observations up to $190 \mathrm{GHz}$ (with TMI, MHS and SSMI/S). The systematic evaluation of WRF + ARTS radiative transfer simulations presents a tool to evaluate the representativity of the different WRF microphysics schemes.

In the present study, a strong sensitivity of the hydrometeor column content to the choice of WRF microphysics scheme has been shown. The WSM6 and the WDM6 schemes model similar hydrometeor mass loadings for all iced species, while the THOM scheme shows higher snow content. The WSM6 has been shown to simulate the highest graupel content followed by the WDM6 scheme, and finally the THOM scheme that produces very little graupel content. An analysis of the domain-averaged vertical distribution of the hydrometeor content nonetheless shows a comparable behaviour of the total ice phase (ice + snow + graupel) for the schemes analysed.

A direct comparison of the simulated and observed brightness temperatures shows that the microphysics schemes in WRF model the overall structure and location of the cloud system fairly well. The large sensitivity to DDA habit choice shown in the simulated brightness temperatures evidences the complexity in characterizing the frozen hydrometeors scattering signal and the importance of improving our knowledge in the subject. Although the present study has not aimed to search for the "best" Liu habit, the statistical performance of the simulated brightness temperatures of the different Liu (2008) habits has been evaluated by analysing the histograms of the observed and simulated brightness temperatures, and using the $\chi^{2}$ test to evaluate how close the simulated distributions are to the observed distributions and hence the repre- 
sentativity of the different WRF microphysics schemes. The resultant bulk scattering properties of each of the Liu (2008) habits are similar for the WSM6 and WDM6 schemes, but different than the THOM scheme. This is due to the different particle size distributions and mass-size relationships. This is reflected in the statistical analysis of the observed and simulated brightness temperatures. For example, the thin hexagonal plates are shown to be one of the least scattering habits in the THOM scheme simulations, but one of the most scattering in the WSM6/WDM6 simulations. The opposite is shown for the sector habits. Nonetheless, disregarding the observed detailed spatial structures, an overall agreement is obtained between the simulated and the observed brightness temperatures, provided that special attention is taken when describing the optical properties of snow and graupel species. The dendrite and the thin hexagonal plate habits show the smallest $\chi^{2}$ values for the THOM scheme WRF simulations, while the sector and dendrite habits show the smallest $\chi^{2}$ values for the WSM6 and WDM6 schemes.

Data availability. Data are available via e-mail requests.

Competing interests. The authors declare that they have no conflict of interest.

Acknowledgements. This research was funded by the CNRS LEFE/IMAGO programme. The authors would like to express their gratitude to the ARTS community for developing and maintaining open-source software.

Edited by: Mark Kulie

Reviewed by: Alan Geer and one anonymous referee

\section{References}

Altinger de Schwarzkopf, M. L. and Necco, G.: Climatologia de los efectos de la conveccion severa en la Republica Argentina, $\mathrm{PhD}$ thesis, Universidad de Buenos Aires (UBA), Facultad de Ciencias Exactas y Naturales (FyCEN), Doctor en Ciencias Meteorologicas, 1988.

Baran, A. J.: From the single-scattering properties of ice crystals to climate prediction: A way forward, Atmos. Res., 112, 45-69, 2012.

Buehler, S., Courcoux, N., and John, V.: Radiative transfer calculations for a passive microwave satellite sensor: Comparing a fast model and a line-by-line model, J. Geophys. Res.-Atmos., 111, 2156-2202, 2006.

Chaboureau, J.-P., Söhne, N., Pinty, J.-P., Meirold-Mautner, I., Defer, E., Prigent, C., Pardo, J. R., Mech, M., and Crewell, S.: A midlatitude precipitating cloud database validated with satellite observations, J. Appl. Meteorol. Clim., 47, 1337-1353, 2008.

Chen, F. and Dudhia, J.: Coupling an advanced land surfacehydrology model with the Penn State-NCAR MM5 modeling system. Part I: Model implementation and sensitivity, Mon. Weather Rev., 129, 569-585, 2001.

Davis, C. P., Evans, K. F., Buehler, S. A., Wu, D. L., and Pumphrey, H. C.: 3-D polarised simulations of space-borne passive $\mathrm{mm} / \mathrm{sub}$ mm midlatitude cirrus observations: a case study, Atmos. Chem. Phys., 7, 4149-4158, https://doi.org/10.5194/acp-7-4149-2007, 2007.

Doherty, A., Sreerekha, T., O'Keeffe, U., and English, S.: Ice hydrometeor microphysical assumptions in radiative transfer models at AMSU-B frequencies, Q. J. Roy. Meteor. Soc., 133, 12051212, 2007.

Draine, B. T. and Flatau, P. J.: Discrete-dipole approximation for scattering calculations, JOSA A, 11, 1491-1499, 1994.

Dudhia, J.: Numerical study of convection observed during the winter monsoon experiment using a mesoscale two-dimensional model, J. Atmos. Sci., 46, 3077-3107, 1989.

Eriksson, P., Buehler, S., Davis, C., Emde, C., and Lemke, O.: ARTS, the atmospheric radiative transfer simulator, version 2, J. Quant. Spectrosc. Ra., 112, 1551-1558, 2011.

Eriksson, P., Jamali, M., Mendrok, J., and Buehler, S. A.: On the microwave optical properties of randomly oriented ice hydrometeors, Atmos. Meas. Tech., 8, 1913-1933, https://doi.org/10.5194/amt-8-1913-2015, 2015.

Field, P., Hogan, R., Brown, P., Illingworth, A., Choularton, T., and Cotton, R.: Parametrization of ice-particle size distributions for mid-latitude stratiform cloud, Q. J. Roy. Meteor. Soc., 131, 1997-2017, 2005.

Galligani, V. S., Prigent, C., Defer, E., Jimenez, C., Eriksson, P., Pinty, J.-P., and Chaboureau, J.-P.: Meso-scale modelling and radiative transfer simulations of a snowfall event over France at microwaves for passive and active modes and evaluation with satellite observations, Atmos. Meas. Tech., 8, 1605-1616, https://doi.org/10.5194/amt-8-1605-2015, 2015.

Gallus Jr., W. A. and Pfeifer, M.: Intercomparison of simulations using 5 WRF microphysical schemes with dual-Polarization data for a German squall line, Adv. Geosci., 16, 109-116, https://doi.org/10.5194/adgeo-16-109-2008, 2008.

Geer, A. J. and Baordo, F.: Improved scattering radiative transfer for frozen hydrometeors at microwave frequencies, Atmos. Meas. Tech., 7, 1839-1860, https://doi.org/10.5194/amt-7-1839-2014, 2014.

Goodman, S. J., Blakeslee, R., J., Koshak, W. J., Mach, D., Bailey, J., Buechler, D., Carey, L., Schultz, C., Bateman, M., McCaul, E., and Stano, G.: The GOES-R geostationary lightning mapper (GLM), Atmos. Res., 125, 34-49, 2013.

Hong, S.-Y. and Lim, J.-O. J.: The WRF single-moment 6-class microphysics scheme (WSM6), J. Korean Meteor. Soc., 42, 129151, 2006.

Hong, S.-Y., Lim, K.-S. S., Lee, Y.-H., Ha, J.-C., Kim, H.-W., Ham, S.-J., and Dudhia, J.: Evaluation of the WRF double-moment 6-class microphysics scheme for precipitating convection, Adv. Meteorol., 707253, https://doi.org/10.1155/2010/707253, 2010.

Janjic, Z. I.: The step-mountain eta coordinate model: Further developments of the convection, viscous sublayer, and turbulence closure schemes, Mon. Weather Rev., 122, 927-945, 1994.

Kim, J.-H., Shin, D.-B., and Kummerow, C.: Impacts of a priori databases using six WRF microphysics schemes on passive microwave rainfall retrievals, J. Atmos. Ocean. Tech., 30, 23672381, 2013. 
Kulie, M. S., Bennartz, R., Greenwald, T. J., Chen, Y., and Weng, F.: Uncertainties in microwave properties of frozen precipitation: Implications for remote sensing and data assimilation, J. Atmos. Sci., 67, 3471-3487, 2010.

Kummerow, C., Barnes, W., Kozu, T., Shiue, J., and Simpson, J.: The tropical rainfall measuring mission (TRMM) sensor package, J. Atmos. Ocean. Tech., 15, 809-817, 1998.

Leinonen, J., Kneifel, S., Moisseev, D., Tyynelä, J., Tanelli, S., and Nousiainen, T.: Evidence of nonspheroidal behavior in millimeter-wavelength radar observations of snowfall, J. Geophys. Res.-Atmos., 117, https://doi.org/10.1029/2012JD017680, 2012.

Li, X., Tao, W.-K., Khain, A. P., Simpson, J., and Johnson, D. E.: Sensitivity of a Cloud-Resolving Model to Bulk and Explicit Bin Microphysical Schemes. Part I: Comparisons, J. Atmos. Sci., 66, 3-21, https://doi.org/10.1175/2008JAS2646.1, 2009a.

Li, X., Tao, W.-K., Khain, A. P., Simpson, J., and Johnson, D. E.: Sensitivity of a Cloud-Resolving Model to Bulk and Explicit Bin Microphysical Schemes. Part II: Cloud Microphysics and Storm Dynamics Interactions, J. Atmos. Sci., 66, 22-40, https://doi.org/10.1175/2008JAS2647.1, 2009b.

Liebe, H. J., Hufford, G. A., and Manabe, T.: A model for the complex permittivity of water at frequencies below $1 \mathrm{THz}$, Int. J. Infrared Milli., 12, 659-675, 1991.

Lim, K.-S. S. and Hong, S.-Y.: Development of an effective doublemoment cloud microphysics scheme with prognostic cloud condensation nuclei (CCN) for weather and climate models, Mon. Weather Rev., 138, 1587-1612, 2010.

Liu, G.: Approximation of single scattering properties of ice and snow particles for high microwave frequencies, J. Atmos. Sci., 61, 2441-2456, 2004.

Liu, G.: A database of microwave single-scattering properties for nonspherical ice particles, B. Am. Meteorol. Soc., 89, 1563, https://doi.org/10.1175/2008BAMS2486.1, 2008.

Magono, C.: Aerodynamic studies of falling snowflakes, J. Meteorol. Soc. Jpn., 43, 139-147, 1965.

Mätzler, C.: Thermal microwave radiation: applications for remote sensing, Vol. 52, Iet, Institution of Engineering and Technology, UK, 2006.

Maxwell-Garnett, J.: Colours in metal glasses, in metallic films, and in metallic solutions. II, Philos. T. R. Soc. Lond., 2, 237-288, 1906.

Meirold-Mautner, I., Prigent, C., Defer, E., Pardo, J. R., Chaboureau, J.-P., Pinty, J.-P., Mech, M., and Crewell, S.: Radiative transfer simulations using mesoscale cloud model outputs: Comparisons with passive microwave and infrared satellite observations for midlatitudes, J. Atmos. Sci., 64, 1550-1568, 2007.

Melsheimer, C., Verdes, C., Buehler, S., Emde, C., Eriksson, P., Feist, D., Ichizawa, S., John, V., Kasai, Y., Kopp, G., Koulev, N., Kuhn T., Lemke, O., Ochiai, S., Schreier, F., Sreerekha, T. R., Suzuki, M., Takahashi, C., Tsujimaru, S., and Urban, J.: Intercomparison of general purpose clear sky atmospheric radiative transfer models for the millimeter/submillimeter spectral range, Radio Sci., 40, 1-25, 2005.
Mezher, R. D. M. and Barros, V.: Climatology of hail in Argentina, Atmospheric Res., 114, 70-82, 2012.

Mlawer, E. J., Taubman, S. J., Brown, P. D., Iacono, M. J., and Clough, S. A.: Radiative transfer for inhomogeneous atmospheres: RRTM, a validated correlated-k model for the longwave, J. Geophys. Res.-Atmos., 102, 16663-16682, 1997.

Morrison, H. C. J. A. and Khvorostyanov, V.: A new doublemoment microphysics parameterization for application in cloud and climate models. Part I: Description, J. Atmos. Sci., 62, 16651677, 2005.

Morrison, H., Thompson, G., and Tatarskii, V.: Impact of Cloud Microphysics on the Development of Trailing Stratiform Precipitation in a Simulated Squall Line: Comparison of One- and Two-Moment Schemes, Mon. Weather Rev., 137, 991-1007, https://doi.org/10.1175/2008MWR2556.1, 2009.

Otkin, J., Hung-Lung, H., and Seifert, A.: A comparison of microphysical schemes in the WRF model during a severe weather event, 2003.

Prigent, C., Aires, F., Wang, D., Fox, S., and Harlow, C.: Sea surface emissivity parameterization from microwaves to millimeter waves, Q. J. Roy. Meteor. Soc., 143, 596-605, 2016.

Salio, P., Hobouchian, M. P., Skabar, Y. G., and Vila, D.: Evaluation of high-resolution satellite precipitation estimates over southern South America using a dense rain gauge network, Atmos. Res., 163, 146-161, 2015.

Saunders, R., Rayer, P., Brunel, P., Von Engeln, A., Bormann, N., Strow, L., Hannon, S., Heilliette, S., Liu, X., Miskolczi, F., Han, Y., Masiello, G., Moncet, J.-L., Uymin, G., Sherlock, V., and Turner, D. S.: A comparison of radiative transfer models for simulating Atmospheric Infrared Sounder (AIRS) radiances, J. Geophys. Res.-Atmos., 112, https://doi.org/10.1029/2006JD007088, 2007.

Silva Dias, M. A. F.: An increase in the number of tornado reports in Brazil, Weather, Climate, and Society, 3, 209-217, 2011.

Skamarock, W. C. and Klemp, J. B.: A time-split nonhydrostatic atmospheric model for weather research and forecasting applications, J. Comput. Phys., 227, 3465-3485, 2008.

Thompson, G., Field, P. R., Rasmussen, R. M., and Hall, W. D.: Explicit forecasts of winter precipitation using an improved bulk microphysics scheme. Part II: Implementation of a new snow parameterization, Mon. Weather Rev., 136, 5095-5115, 2008.

Wang, D., Prigent, C., Aires, F., and Jimenez, C.: A statistical retrieval of cloud parameters for the millimeter wave Ice Cloud Imager on board MetOp-SG, IEEE Access, 5, 4057-4076, 2016.

Zipser, E. J., Cecil, D. J., Liu, C., Nesbitt, S. W., and Yorty, D. P.: Where are the most intense thunderstorms on Earth?, B. Am. Meteorol. Soc. 87, 1057, https://doi.org/10.1175/BAMS-87-8-1057, 2006. 